\title{
Adsorption Kinetics of Toxic Metals from Brewery Waste Water Using Adsorbent Prepared from Borassus aethiopum
}

\author{
Adaji Idoko Johnson', Chukwu Emmanuel Ogwu' ${ }^{2}$ Peter K. Agabue ${ }^{3}$, Daliyas Yunana \\ Bachi $^{4}$, Faluyi Marvellous Oluwaferanmi ${ }^{5}$, Okoro Amaka Desire ${ }^{6}$ \\ 1, 2, 3,4 Richflood Laboratories Limited, Abuja \\ ${ }^{5}$ Jawura Environmental Services Limited, Port-Harcourt \\ ${ }^{6}$ Federal University of Technology, Owerri, Nigeria \\ DOI - http://doi.org/10.37502/IJSMR.2021.4602
}

\begin{abstract}
A comparative study was carried out on the remediation of brewery effluent $\left(\mathrm{B}_{\text {eff }}\right)$ using derived adsorbent (Untreated and treated) and commercial activated carbon. Preliminary study and characterization of the brewery effluent, derived adsorbent and commercial activated carbon was recorded, with result showing physico-chemical properties of the effluent falls within, lower and higher than discharge limit outlined by NESREA and WHO. Result of the physico-chemical and instrumental characterization of the adsorbents indicates that the adsorbents are within valid ranges as compared to literature. Column adsorption study was carried out to study the effect of experimental variables $(\mathrm{pH}$, time and temperature), while $\mathrm{RE} \%$ of $\mathrm{Cd}, \mathrm{Cr}, \mathrm{Cu} \& \mathrm{~Pb}$ by the adsorbents were calculated and recorded for all experimental condition. These variables in the order of UAD, TAD \& CAC were estimated, reported and percent removal at the optimal condition of $40.721 \mathrm{mg} / \mathrm{L}, 2,20 \mathrm{~min}$ and $313 \mathrm{~K}$ for initial concentration, $\mathrm{pH}$, time and temperature respectively. The equilibrium studies for the sorption of $\mathrm{Cd}, \mathrm{Cr}, \mathrm{Cu} \& \mathrm{~Pb}$ were investigated using three widely used kinetic models (Pseudo first-order, Pseudo second-order and Elovich kinetic models), film and intraparticle mode of transport were studied. The rate law of the adsorption kinetics is best explained using the Pseudo-second order kinetic model, intraparticle diffusion model gave the highest regression coefficient $\left(\mathrm{R}^{2}\right)$ for the adsorbents used, thermodynamic study was done using Van't Holf models. The efficiency in remediation of effluent using derived adsorbents and commercial activated carbon at 95\% confidence interval shows that there is statistical significant difference for UAD and CAC hence the need to follow the analysis with post-hoc test arose, while TAD indicated no level of statistical significant difference and thus requires no post-hoc test. This implied that the TAD is an economically viable approach to combat remediation challenges in the removal of $\mathrm{Cd}, \mathrm{Cr}$, and $\mathrm{Cu} \& \mathrm{~Pb}$ from brewery waste water. Adsorbent characterization using FTIR and SEM gave results that justified the use of TAD in this study.
\end{abstract}




\section{5 | International Journal of Scientific and Management Research 4(6) 14-52}

Keywords: Adsorption, Borassus aethiopum, Comercial activated carbon, Heavy metals, Kinetics, Wastewater, Treated Adsorbent, Untreated adsorbent.

\section{Introduction}

Water is very important both as generally acceptable solvent as well as a vital precursor for metabolic process in human system. The existence of human life depends essentially upon clean and fresh water. However, the supply of quality water worldwide is questionable due to the high level of contaminant in the water body, which has created the gap to meet standards (Pradeep, 2009).

The contamination of water/wastewater by heavy metal is of global concern because the dumping of these toxic metals into water and soil environments impacts negatively both on the ecosystem and human health. The quality of water over the years now has shown the deteriorating effect mainly as a result of human activities (anthropogenic) such as unskilled usage of natural resources, overpopulation, numerous industrialization and unplanned urbanization. The non-biodegradable nature (the tendency accumulate for a long time) of heavy metals are taken to be the most significant pollutant of water source (Anirudhan et al., 2007). Some of these metal ions are cadmium, chromium copper, lead, nickel. For example, the toxic effect of heavy metal could come from drinking water contamination (lead pipes), ingestion through food chain or near sources of emission in an increased ambient air concentration. The industrial usage of heavy metal has contributed a lot of metallic substance that is present in the natural water body (Iwahori et al., 2014). Furthermore, the more information about the significance of general impacts due to the present environmental strategies has dragged the research community close to the development of reliable, economic and environmental friendly steps with removal potential of pollutants from water/wastewater and also to protect the health of the people in the affected areas (Marin et al., 2009).

The various traditional treatment technologies with records of different level of success to reduce water pollution have been used over the years. However, the disadvantages of most of these processes are high maintenance and operational costs, difficult procedure for the treatment and production of toxic sludge (Tchobanoglous et al., 2003; Bhatnagar et al., 2015). Comparatively, adsorption method is taken instead as the better option in water/wastewater treatment because of the convenience, simple design and ease of operation (Ali et al., 2012). Adsorption process is employed for the treatment of soluble pollutants that are left after chemical oxidation and subsequent biological phase in wastewater treatment plant. The most widely known and adopted adsorbent today is the activated carbon. It is globally employed for the removal of different pollutants (ratio of 1:2 of dyes and heavy metals) from water. But it has limitation in its use in wastewater treatment due to its high cost with other problems such as the disposal of the end-of-life sorbent with unique strategies than disposal or the adsorbent regeneration capacity (De Feo and De Gisi, 2014; Gautam et al., 2014). 
Different variety of agricultural solid waste has been examined for their potential to remove different kinds of pollutants from water/wastewater. The research community's goal is to replace activated carbons from the state-of-the-art with the by-products from different activities like agriculture and industry. These waste products pose various forms of disposal problems as the result of their bulk volume, toxic and physical nature (i.e. scrap tyres, petroleum waste and agricultural waste). This brings two-fold sanity to the environment if these wastes are converted into low cost adsorbent. Firstly, the low cost adsorbent if designed can control the pollution of water. Secondly, the volume of waste (by-products) could be controlled to the minimal level (Marin et al., 2009).

\section{Literature Review}

\section{Wastewater Pollution}

The water pollution is of great concern due to its global risk and its effect to society (the manner of environmental ravage) and its rated eight (8) planetary risk listings due to their probable occurrence (the occurrences within the past decade) according to the World Economic Forum (Bernardo et al., 2009).

The task of providing and ensuring clean and fresh water is in a rapid growth with the increase in population of the world, there are over 0.78 billion people in the universe who do not have contact to clean water resources which is causing major health hazards (WHO, 2013). Moreover, the estimate of 9 billion of habitants by 2050 shows relatively that water supply will become even more vital in the future (El-Rahman and Gepreel, 2013). Global climate change also warms up to take away the already large portion of the scarce fresh water resources as a result of the intrusion sea water, municipal and industrial waste that always pollute water supplies and large amounts of water are used to produce increasing quantities of energy from local sources (Brame et al., 2011). Clean water is also an important feedstock in a rank of key industries such as food, pharmaceutical and electronics (Savage and Diallo, 2005).

Though the pollutants nature may differ, which are basically due to inadequate clean-up, algal blooms enriched the phosphorus and nitrogen comprised in human and animal waste, fertilizers and detergents, chemicals, pesticides, the widespread and inefficient irrigation which results in salinity, heavy metals and high sediment load resulting from upstream soil erosion (Theron et al., 2008). Amidst the water pollutants, heavy metals have received more importance in view of their toxicity, persistence and bio-magnification (Kadirvelu et al., 2001). There are several pathways that heavy metal can easily enter into food chain and cause continuous toxic by gathering slowly in the entire life span of the living organisms. However, reliable measures are required to find and eliminate heavy metals from environmental and biological samples (Ge et al., 2012).

Magnitude of energy has been invested into proper removal of heavy metal ions. The most conventionally used methods for removal of toxic metals from water/wastewaters are chemical precipitation, evaporation, ion exchange, reverse osmosis, membrane filtration and adsorption. However, finding shows interest in the production of effective and low cost adsorbent (needed in 


\section{7 | International Journal of Scientific and Management Research 4(6) 14-52}

adsorption process) in place of high cost adsorbent for wastewater treatment (Ngah and Hanafiah, 2008; Kobya et al., 2005).

\section{Industrial (Brewery) Wastewater Pollution}

The present-day society is faced with environmental challenges that requires urgent solutions even the food industry is in a precise manner of yielding quantity of wastes that are usually capable of being decomposed (Chae, et al., 2009). The wastewaters generated as a results of washing and cooling units have an elevated level of chemical oxygen demands (CODs) but are not harmful because of high rate of organic matter presence in the water which consists of starch, sugar, and protein (Speece, 1996).Amongst biological processes practically engaged for the treatment of brewery wastewater are: batch sequencing aerobic reactor (Wang et al, 2007), ultrafiltration membrane cross-flow anaerobic reactors (Ince et al., 2000), and sludge blanket upflow anaerobic reactors (Kida et al., 1994). Biological methods of treatments are precise key for treating wastewater, and this demand an elevated level of energy input. Hence, requires energy demand reduction for the treatment of wastewater (Parawira et al., 2005).

\section{Heavy Metals and its Environmental Impacts}

Metal ions are those metals that are generally considered to have their density of about $5 \mathrm{~g} / \mathrm{cm}^{3}$ (Babel and Kurniawan, 2003; Wang et al., 2013). Heavy metals are important pollutant of the environment and their toxic level poses a significant threat of progressing importance for ecological, environmental, providing nutrition and evolutionary reasons. They are metallic element that is harmful (non- decomposable) even at low concentrations (Nagajyoti et al., 2010). Reasons being that, non-decomposable metal ions are most inorganic in nature and thus causes cancer even at low concentrations. Heavy metals are commonly found in industrial effluents such as chemical industries, battery industries, dyes and pigments industries, textile industries, mining industries, pharmaceutical industries, petroleum industries, fertilizer industries. The USEPA has discovered these as preference and toxic pollutants are checked before allowing into the environment (EPA, 2015). The sources of heavy metal pollution can be either natural or anthropogenic (human activities), the natural sources of heavy metal pollution in the environment are geologic parent material or rock out-cropping while the anthropogenic sources are; agricultural sources (organic and inorganic fertilizers), industrial sources (smelting, recycling of metals and metal finishing, mining etc.) and atmospheric deposition sources (leakage, asphalt wear, tyres, vehicle exhaust) (Karvelas et al., 2003; Nagajyoti et al., 2010). Other sources of heavy metal pollution are; the wood processing industry that employ the use of chromate-copper-arsenate for treatment of wood, inorganic pigment manufacturing industry using pigment made of chromium compounds and cadmium sulfide etc. These are responsible for large amount of wastewater, sludge and residue that are referred to as hazardous wastes (Barakat, 2011).

\section{Heavy Metal Removal Technologies}

Wastewaters laden with heavy metals have been treated with different techniques with the aim of reducing the production of this wastewater and to improve the quality of the treatment effluent 


\section{8 | International Journal of Scientific and Management Research 4(6) 14-52}

(Kurniawan et al., 2006). Although, other treatment such as chemical precipitation, ion exchange and adsorption can be used for the removal of heavy metals from the wastewater, each of the metals has their specific advantage and disadvantage (O'connell et al., 2008).

\section{Adsorption Process}

Adsorption is the transfer of ions from solution phase to the solid phase. Sorption actually describes a group of processes namely; adsorption and precipitation reactions (Zhao et al., 2011). Adsorption is a mass transfer process which involves the accumulation of substances at the interface of two phases, which are liquid-liquid, gas-liquid, gas-solid or liquid-solid interface (Barakat, 2011). The substance being adsorbed is the adsorbate and the adsorbing material is called the adsorbent. The properties of adsorbate and adsorbent are unique due to their constituent (Coonery, 1999). Adsorption is now known as an effective and economic process for heavy metal wastewater treatment. The adsorption process gives flexibility in design, operation and in most cases will generate high quality treated effluent. Moreover, adsorption is sometimes reversible, adsorbent can be reproduced by a proper desorption method (Fu and Wang, 2011). Sorbents are generally employed as a separation media in water treatment to eliminate both organic and inorganic pollutants from contaminated water (Savage and Diallo, 2005). If the interaction between the solid surface and the adsorbed molecules has a physical nature, the process is called physio-sorption. The attraction interaction is Van der Waals forces, because it occurs closer to the critical temperature of the adsorbed substances and as a result they are weak and the process is a reversible reaction. Physical adsorption is followed by a reduction in free energy and entropy of the adsorption system and the process is called exothermic. On the other hand, if the force of attraction between adsorbed molecules and the solid surface occurred as a result of chemical bonding, the process of adsorption is termed chemisorption. This process occurs only as a monolayer, the substances that is chemically adsorbed to the solid surface cannot be easily removed due to the stronger forces involved. These processes can occur simultaneously or alternatively in a conducive condition (Coonery, 1999).

\section{Adsorbents}

Activated carbon is the most widely used adsorbent. It is a highly porous, amorphous solid consisting of micro crystallites with a graphite lattice, usually prepared in small pellets or a powder. It can remove a wide variety of toxic metals. Some widely used adsorbents for adsorption of metal ions include activated carbon. Natural material or certain waste from industrial or agricultural operation is one of the resources for low cost adsorbents. Generally, these materials are locally and easily available in large quantities. Therefore, they are inexpensive and have little economic value. Scattered research has already been conducted on a wide variety of sorbents. Some of the reported low-cost sorbents include bark/tannin-rich materials, lignin, chitin/chitosan, dead biomass, seaweed/algae/alginate, xanthate, zeolite, clay, ash, peat moss, bone gelatin beads, leaf mould, moss, iron-oxide-coated sand, modified wool modified cotton (Mohana et al., 2007). 


\section{9 | International Journal of Scientific and Management Research 4(6) 14-52}

Activated alumina is a filter media made by aluminum ore so that it becomes porous and highly adsorptive. It can also be described as a granulated form of aluminum oxide. Activated alumina removes a variety of contaminants that often co-exist with fluoride such as excessive arsenic. The medium requires periodic cleaning with an appropriate regenerator such as alum or acid in order to remain effective. Activated alumina has been used as an effective adsorbent especially for point of use applications. The main disadvantage of activated alumina is that the adsorption efficiency is highest only at low $\mathrm{pH}$ and contaminants like arsenates must be peroxided to arsenates before adsorption in addition, the use of other treatment methods would be necessary to reduce levels of other contaminants of health concern (Satapathy and Natarajan, 2006).

Silica gel is a non-toxic, inert and efficient support and is generated by decreasing the $\mathrm{pH}$ value of the alkali silicate solution to less than ten. The solubility of silica is then reduced to form the gel and as the silica begins to gel, cells in silica are trapped in a porous gel, which is a three-dimensional $\mathrm{SiO}_{2}$ network. Porous silica gel is an inorganic synthetic polymeric matrix often used to entrap cells and its use for entrapment is called the sol-gel technique. Reactive sites of silica gel exist in large numbers, and therefore, the number of immobilized organic molecules is high, which result in good sorption capacity for metal ions (Neeta and Gupta, 2016).

The low costs from agricultural by-products are the most available raw materials for adsorbent used in water and wastewater treatment compared to the conventionally known activated carbon due to their minimization of chemical and biological sludge production, low cost, possibility of metal recovery, high sorption efficiency, and non-generation of secondary waste problems. Some of the solid agricultural wastes are; coconut shells (Pillai et al., 2014), coir pith (Namasivayam et al., 2001), orange peel, cassava peel, citric acid (Li et al., 2007), agave bagasse, corn cob, plum kernel, cane pith (Juang et al., 2001), sugarcane bagasse (Khoramzadeh et al., 2013), lentil shell, rice shell (Aydin et al., 2008), rice straw (Ding et al., 2012), neem bark (Maheshwari et al., 2015). Researches have been carried out for the removal of several heavy metal ions from aqueous solutions. The main components presents in the agricultural solid waste responsible for the removal of metal ion from water/wastewater includes; hemicellulose, lipids, lignin, hydrocarbons, extractives, proteins, starch, simple sugars and water of various functional groups with capacity sorption potentials for different pollutants (Bhatnagar et al., 2015).

\section{Borassus palm}

This is a monotypic genus named Borassus aethiopum (Palmyra Palm, Fan Palms), native to tropical regions of Africa, Asia and New Guinea. This palm grows up to $30 \mathrm{~m}(98 \mathrm{ft})$ high with robust trunks and distinct leaf scars; some species the trunk develops a distinct swelling just below the crown, though for unknown reasons. The leaves are 2-3 m long, fan-shaped, and with spines along the petiole margins). The leaf sheath has a distinct cleft at its base, through which the inflorescences appear; old leaf sheaths are retained on the trunk, but fall away with time. All Borassus palms are dioecious, with male and female flowers on separate plants; male flowers are 
less than $1 \mathrm{~cm}$ long and in semi-circular clusters, sandwiched between leathery bracts in pendulous catkins; female flowers are $3-5 \mathrm{~cm}$ wide, globe-shaped and solitary, sitting directly on the surface of the inflorescence axis. The fruits are $15-25 \mathrm{~cm}$ wide, roughly spherical and each contain 1-3 large seeds. Depending on species, fruit color varies from black to brown, yellow or orange; the fibrous pulp is aromatic and sweet to taste. Each seed is enclosed in a woody endocarp, which protects it when the fruit is consumed by elephants, monkeys and other frugivores. At germination, the young seedling extends downwards into the soil and only a few leaves are visible above ground; this provides some protection against frequent fires in its savanna habitat; after an indeterminate number of years (the establishment phase), the seedling forms a stem and quickly grows above the savanna vegetation, where it is then less vulnerable to fire (Bailey, 2011).

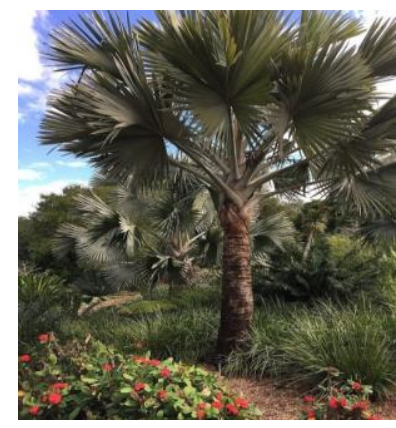

(a) B. aethiopum Tree

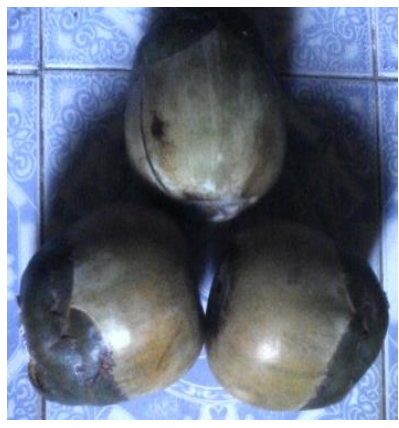

(b) B. aethiopum Nuts

Plate 1

\section{Materials and Methods}

\section{Materials}

\section{Apparatus and equipment}

Oven, Desiccators, Muffle furnace, Forceps, Glassware, litmus paper, Filter papers, Steam bath, Centrifuge, Thermometer, Incubator, Handheld Colorimeter (DR/890), Turbimeter and Dissolved Oxygen meter. Hot plate or gas burner, Biochemical Oxygen Demand bottles, Filtration apparatus, Analytical balance, FTIR (Agilent Technologies Cary 630), Phenom proX model, SEM (MVE016477830), AAS (Varian AA240FS), pH multi-meter (Jenway 4510).

\section{Reagents and procurement}

All reagents used were of analytical grade and were prepared in line with standard methods as described in the Manual for Standard Analytical Procedures (1999), except otherwise Stated. Other procedures used are duly acknowledged. Reagents used in this study include: Ethyl Alcohol (95\%), Starch and Methylene blue were procured from FISONS Science Equipment, Wembley Middlesex England. $\mathrm{HCl}, \mathrm{HNO}_{3}, \mathrm{AgCl}, \mathrm{CuSO}_{4}, \mathrm{H}_{2} \mathrm{SO}_{4}, \mathrm{Na}_{2} \mathrm{~S}_{2} \mathrm{O}_{3}$, and $\mathrm{HClO}_{4}$ were supplied by JHD, Guangdong Guanghua Science Tech Company Limited, Shantou, China. KHP, 
$\mathrm{NaOH}$, Bromocresol Green indicator, barium chloride crystals, ferroin indicator solution, methyl orange indicator, $\mathrm{MnCl}_{2}, \mathrm{MgSO}_{4}$, and $\mathrm{AgNO}_{3}$ were procured from KEM LIGHT laboratories PVT limited, Mumbai India. Activated carbon, $\mathrm{MnSO}_{4}, \mathrm{ZnC}_{4} \mathrm{H}_{6} \mathrm{O}_{4}, \mathrm{C}_{8} \mathrm{H}_{4} \mathrm{KO}_{4}, \mathrm{~K}_{2} \mathrm{Cr}_{2} \mathrm{O}_{7}$, and $\left(\mathrm{NH}_{4}\right)_{2} \mathrm{Fe}\left(\mathrm{SO}_{4}\right)_{2} \cdot 6 \mathrm{H}_{2} \mathrm{O}$ were supplied by $\mathrm{BDH}$.

\section{Study Area}

The study area, Kaduna town lies at an altitude of $10.20 \mathrm{~N}$ and longitude 7.24 E and is the capital Kaduna State in the Northern part of Nigeria. Kaduna has a population of about 2 million inhabitants. Kaduna has an industrial layout in Southern part- makera/kakuri with many industries located in the layout, chief amongst them which are Nigeria Breweries, Supper phosphate Fertilizer Company, Turners Asbestos Products (TAP), Textile Company and Military Factories, DICON, Defense Industries Corporation of Nigeria.

\section{Sampling}

Sampling was carried out in accordance with methods described by Foo and Hammed, (2010) and Aydin et al., (2008). Effluent samples were collected and homogenized to obtain a representative sample; first by stirring, before lowering a pre-cleaned $4 \mathrm{~L}$ glass bottle (previously washed with $0.1 \mathrm{M} \mathrm{HNO}_{3}$ before rinsed with distilled water) into different depths of the effluent, allowed to over flow before withdrawing, then the bottle is sealed before storing at $4{ }^{\circ} \mathrm{C}$ till required for further analysis. $\mathrm{PH}$ and conductivity were determined in situ. Effluent sample to be used for metal analysis was treated with $\mathrm{HNO}_{3}$ (conc.) in order to lower the $\mathrm{pH}$ of the sample to less than 2 before refrigeration. Method and duration of the preservation adopted was as described by APHA (1995).

\section{Methods}

ASTM standard of analytical methods were adopted in this work.

\section{Sampling and sample identification}

The plant samples Borassus aethiopum was collected from Achokpa, a village in Igalamela L.G.A of Kogi state. The sample was taken for proper identification in the Department of Taxonomy Ahmadu Bello University, Kaduna State.

\section{Sample pretreatment and storage}

The sampled plants were washed and rinsed with distilled water, sun dried, ground into powder, screened to obtain the target particle size, washed many times with distilled water to remove the surface impurities, then oven dried at $110^{\circ} \mathrm{C}$ and stored at room temperature (Aljeboree et al., 2014).

\section{Preparation of adsorbents}

i. Untreated activated carbon (UAC) 
According to Amuda et al., (2007), the plants sample of spongy mesocarp from Borassus aethiopum were collected, washed and rinsed with distilled water, dried, ground into powder and screened into a target particle size.

ii. Treated activated carbon (TAC)

According to Sreekal et al., (1997), the targeted particle size of the adsorbent was treated with alkali known as mercerization, this was done by leaving adsorbent in 5\% $\mathrm{NaOH}$ solution for 24 hours at room temperature $\left(25 \pm 3{ }^{\circ} \mathrm{C}\right)$, then washed with distilled water and acetic acid, rinsed until filtrate becomes neutral, the chemically treated adsorbents was oven dried at $110{ }^{\circ} \mathrm{C}$ to a constant weight, sieved to remove the unwanted particles and stored in an air tight container.

iii. Commercial activated carbon (CAC) was used as control standard.

\section{Table 1: Adsorbent codes and description}

\section{S/NO}

1 .

2.

3. Adsorbent Code

UAD

TAD

CAC

\section{Description}

Untreated Adsorbent (Borassus aethiopum)

Treated Adsorbent (Borassus aethiopum)

Commercial Activated Carbon (Control

Standard)

\section{Characterization of adsorbents}

The classical and instrumental techniques of characterization for adsorbents were carried out using the following:

i. Instrumental technique of characterization includes: Scanning electron microscopy (SEM) and Fourier transform infra-red (FT-IR) spectrometry.

ii. Classical technique of characterization includes: Bulk density, Moisture content, Ash content and Iodine number test

\section{Digestion of adsorbents}

To $50 \mathrm{~mL}$ effluent sample, $9 \mathrm{~mL}$ of freshly prepared acid mixture $\left(65 \% \mathrm{HNO}_{3}\right.$ was added and $37 \% \mathrm{HCl})$ was added. Then, the mixture was boiled gently over a water bath $\left(95{ }^{\circ} \mathrm{C}\right)$ for $5 \mathrm{hrs}$ (until the sample had completely dissolved) (Mohammed et al., 2013). During the digestion, the inner walls of the beakers were washed with $2 \mathrm{~mL}$ of deionized water to prevent the loss of the sample, and at the last part of the digestion processes, the samples were filtered with Whatman 42 (2.5- $\mu \mathrm{m}$ particle retention) filter paper. The sample was quantitatively transferred to a volumetric flask and diluted to $50 \mathrm{~mL}$ volume with deionized water and analysed for heavy metal (Cr) using AAS.

\section{Pre-treatment of the commercial activated carbon}

This was carried out to increase the metal uptake. Virgin CAC (100 g) was washed with distilled and deionized water and dried in an oven at $105{ }^{0} \mathrm{C}$ for $24 \mathrm{hrs}$. After drying, the adsorbent was removed from the oven and allowed to equilibrate inside a desiccator. This step is necessary since dried carbon can gain as much as 5-10\% in weight when exposed to ambient temperature and humidity (Batt and Shah, 2013). 
23 | International Journal of Scientific and Management Research 4(6) 14-52

\section{Physicochemical Parameter of Brewery Wastewater}

i. The physicochemical parameters of the brewery wastewater will be investigated for the following: pH, Conductivity, BOD, COD, turbidity and Heavy metals.

ii. The parametric factors will be studied for: Effect of dosage (Packing), Effect of $\mathrm{pH}$ and Effect of contact time to optimize the parameters.

\section{Results and Discussions}

\section{Physical Examination of Sampling Site and Sampling}

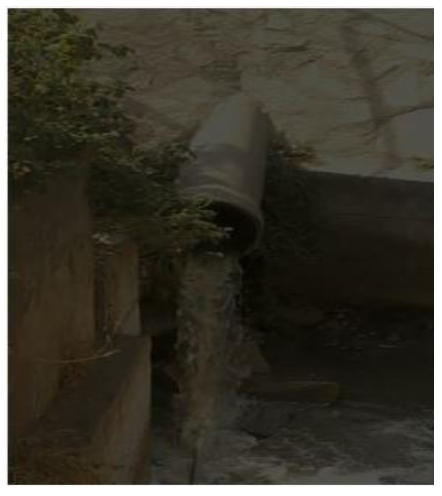

(a) Effluent Discharge Point

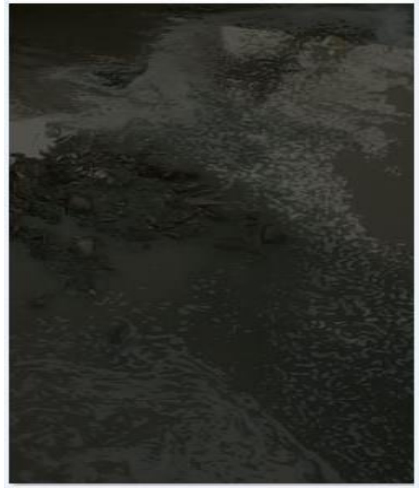

(b) Surrounding Point

Plate 20

\section{Physico-chemical Parameters}

Report of the physic-chemical parameters of Brewery effluent and adsorbents were reported and presented in the Table 2 and 3 respectively.

Table 2: Physico-chemical Properties of Brewery Effluent and Discharge Limit

\begin{tabular}{|c|c|c|c|}
\hline Parameters & \multicolumn{3}{|c|}{ Values } \\
\hline & Current Study & NESREA & WHO \\
\hline $\mathrm{pH}$ & 6.512 & $6.0-9.0$ & $6.5-85$ \\
\hline Conductivity $(\mu \mathrm{S} / \mathrm{cm})$ & 12.68 & - & 12 \\
\hline Turbidity $(\mathrm{mg} / \mathrm{L})$ & 39.3 & 5 & 5 \\
\hline COD $(\mathrm{mg} / \mathrm{L})$ & 15.48 & $60-90$ & 250 \\
\hline BOD $(\mathrm{mg} / \mathrm{L})$ & 8.991 & $30-50$ & 30 \\
\hline
\end{tabular}

Table 3: Physico-chemical Properties of Adsorbents Analyses

\begin{tabular}{|c|c|c|c|}
\hline Parameters & \multicolumn{3}{|c|}{ Current Study } \\
\hline & UAD & TAD & CAC \\
\hline Ash $(\%)$ & $12.21 \pm 0.370$ & $4.22 \pm 0.600$ & $7.10 \pm 0.030$ \\
\hline Bulk Density $\left(\mathrm{g} / \mathrm{cm}^{3}\right)$ & $0.09 \pm 0.020$ & $0.02 \pm 0.010$ & $0.10 \pm 0.020$ \\
\hline Iodine Number $(\mathrm{mg} / \mathrm{g})$ & $124.14 \pm 0.05$ & $89.19 \pm 0.06$ & $250.36 \pm 0.30$ \\
\hline
\end{tabular}




\begin{tabular}{|c|c|c|c|}
\hline Moisture (\%) & $7.08 \pm 0.040$ & $3.12 \pm 0.050$ & $6.67 \pm 0.070$ \\
\hline
\end{tabular}

\section{SEM Characterization}

The surface morphology of the activated carbon samples by scanning electron microscopy. Plate 3, 4 \& 5 showed the micrographs of untreated adsorbent (UAD), treated adsorbent (TAD) and commercial activated carbon (CACThe surface morphology of the activated carbon samples by scanning electron microscopy. Plate $3,4 \& 5$ showed the micrographs of untreated adsorbent (UAD), treated adsorbent (TAD) and commercial activated carbon (CAC).

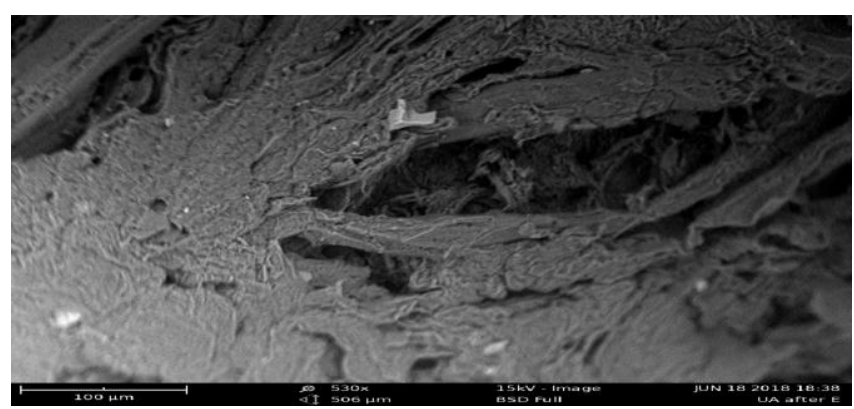

Plate 1: SEM Micrograph of UAD

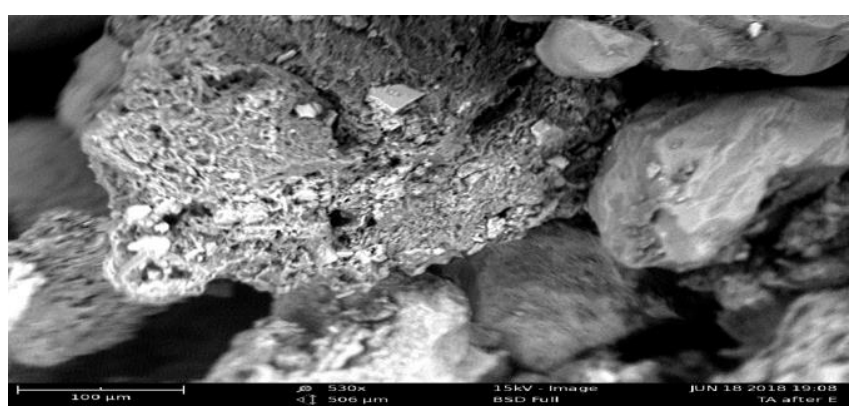

Plate 2: SEM Micrograph of TAD

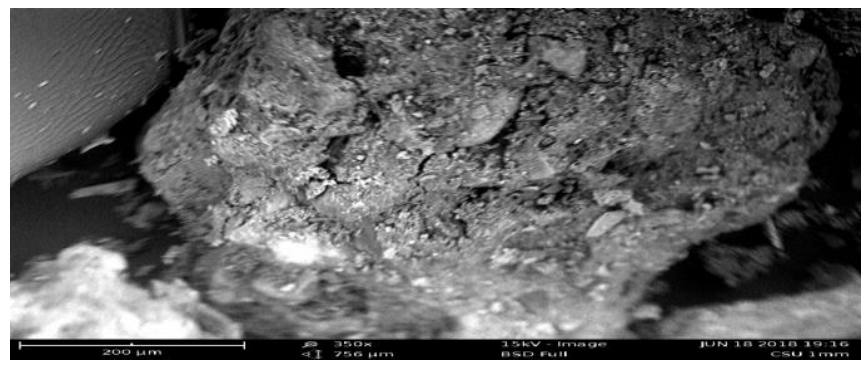

Plate 3: SEM Micrograph of CAC

\section{FTIR Characterization}

FTIR spectra of untreated adsorbent, treated adsorbent and commercial activated carbon are showed in Figures 1, 2 \& 3 respectively.

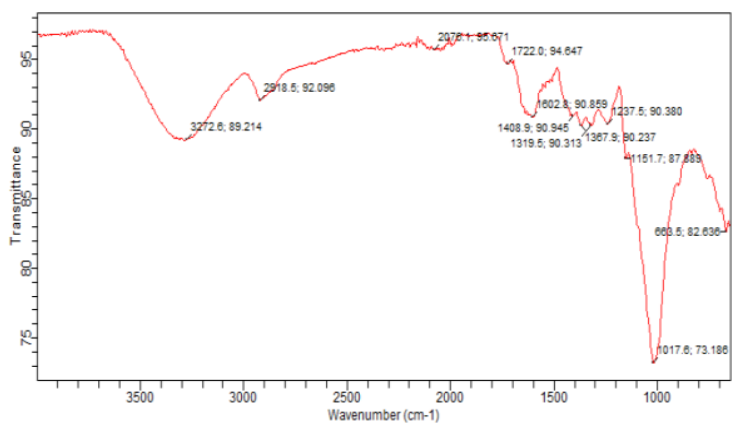

Figure 1: FTIR Spectrum of UAD

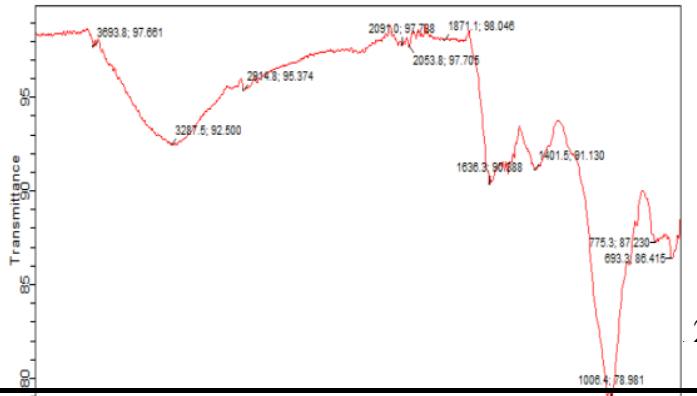

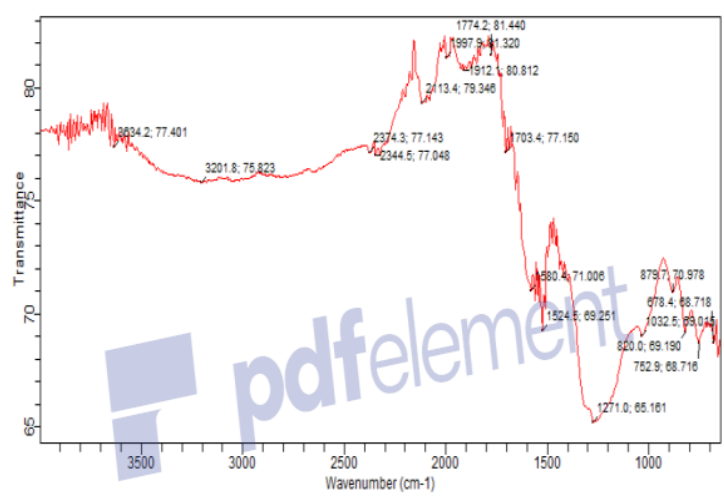

Figure 2: FTIR Spectrum of TAD 
25 | International Journal of Scientific and Management Research 4(6) 14-52

Figure 3: FTIR Spectrum of CAC

Table 4: Comparative FTIR Spectra Characteristics of UAD, TAD and CAC

\begin{tabular}{|c|c|c|c|c|c|}
\hline \multirow{2}{*}{$\begin{array}{l}\text { Group } \\
\text { Freq }\left(\mathrm{cm}^{-}\right. \\
\text {1) }\end{array}$} & \multirow[t]{2}{*}{ Functional Group } & \multicolumn{3}{|c|}{ Observed Freq. } & \multirow{2}{*}{$\begin{array}{l}\text { Assignment } \\
\text { O-H stretch }\end{array}$} \\
\hline & & UAD & TAD & $\mathrm{CAC}$ & \\
\hline $\begin{array}{l}4000- \\
3500\end{array}$ & Alcohols & --- & 3634.2 & 3693.8 & O-H stretch \\
\hline $\begin{array}{c}3499- \\
3000\end{array}$ & Amines & 3272.6 & 3201.8 & 2387.5 & N-H stretch \\
\hline $\begin{array}{c}2999- \\
2500 \\
\end{array}$ & Alkanes & 2918.5 & --- & 2914.8 & SP3 C-H stretch \\
\hline \multirow{6}{*}{$\begin{array}{c}2499- \\
2000 \\
\end{array}$} & Carboxylic Acids & --- & 2374.3 & --- & $\mathrm{O}-\mathrm{H}$ of $-\mathrm{CO} 2 \mathrm{H}$ \\
\hline & Nitriles & --- & 2344.5 & --- & $\mathrm{C} \equiv \mathrm{N}$ stretch \\
\hline & Alkynes & --- & 2113.4 & --- & $\mathrm{C} \equiv \mathrm{C}$ stretch \\
\hline & Aromatic compounds & --- & --- & 2091.0 & SP2 C-H stretch \\
\hline & & 2076.1 & --- & --- & \\
\hline & & --- & --- & 2053.8 & \\
\hline \multirow[t]{10}{*}{$\begin{array}{c}1999- \\
1500\end{array}$} & Aromatic compounds & --- & 1997.9 & --- & $\begin{array}{c}\text { Aromatic } \\
\text { overtones of ring } \\
\text { bends }\end{array}$ \\
\hline & & --- & 1912.1 & --- & \\
\hline & & --- & --- & 1871.1 & \\
\hline & Ketones/Esters & --- & 1774.2 & --- & $\mathrm{C}=\mathrm{O}$ stretch \\
\hline & Aldehydes & 1722.0 & --- & --- & \\
\hline & Esters/Carboxylic Acids & --- & 1703.4 & --- & \\
\hline & Alkenes & --- & --- & 1636.3 & $\mathrm{C}=\mathrm{C}$ stretch \\
\hline & Aromatic compounds & 1602.8 & --- & --- & \\
\hline & & --- & 1580.4 & --- & \\
\hline & & --- & 1524.5 & --- & \\
\hline \multirow{6}{*}{$\begin{array}{c}1499- \\
1000 \\
\end{array}$} & Aromatic compounds & 1408.9 & --- & $\begin{array}{ll}-- \\
-1\end{array}$ & $\mathrm{C}=\mathrm{C}$ stretch \\
\hline & & --- & --- & 1401.5 & \\
\hline & & 1367.9 & --- & --- & \\
\hline & Amines & 1319.5 & --- & --- & C-N stretch \\
\hline & & 1237.9 & --- & --- & \\
\hline & & 1151.7 & --- & --- & \\
\hline
\end{tabular}

\section{Diluent}


26 | International Journal of Scientific and Management Research 4(6) 14-52

Table 5 presented the conversion for dilution of the volume of the brewery effluent $(\mathrm{mL})$ with volume of distilled water $(\mathrm{mL})$ at a given ratio and percentage rating.

Table 5: Conversion for Dilution Ratio on Metal Up-take on Derived Adsorbents and CAC

\begin{tabular}{|c|c|c|c|}
\hline Volume of Effluent (mL) & Volume of Distilled Water $(\mathbf{m L})$ & Ratio & Percentage (\%) \\
\hline 10 & 50 & $1: 5$ & 20 \\
\hline 20 & 40 & $2: 4$ & 50 \\
\hline 30 & 30 & $3: 3$ & 100 \\
\hline 40 & 20 & $4: 2$ & 200 \\
\hline 50 & 10 & $5: 1$ & 500 \\
\hline
\end{tabular}

\section{Equilibrium Phase Concentration}

Charts presented as Figures 4, 5, $6 \& 7$ showed the $\mathrm{Ce}(\mathrm{mg} / \mathrm{L})$ comparing the parametric factors of $\mathrm{Cd}, \mathrm{Cr}, \mathrm{Cu}$ and $\mathrm{Pb}$ adsorption onto $\mathrm{UAD}, 7$

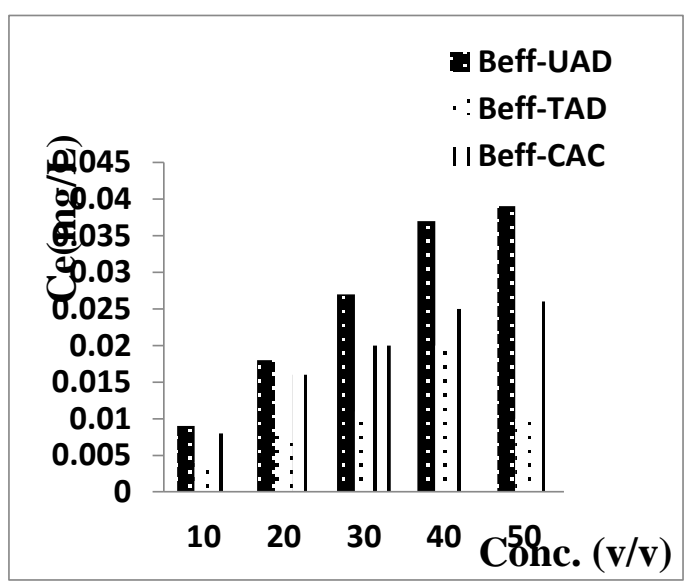

Figure 4: Effect of Diluent on Equilibrium Phase Concentration of Cd Uptake on Adsorbents

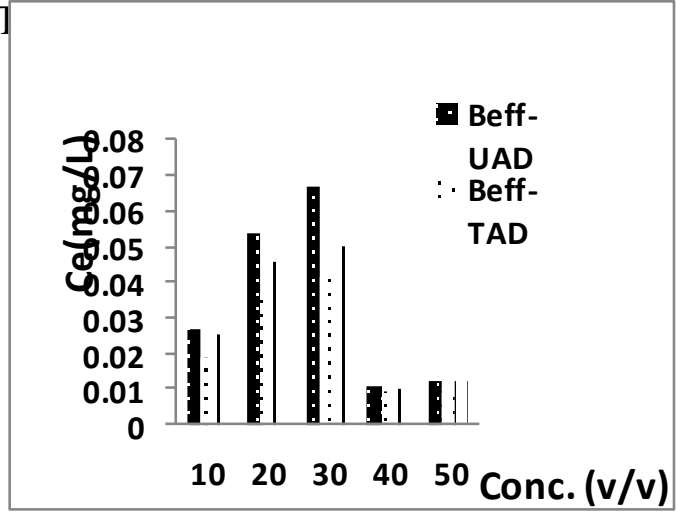

Figure 5: Effect of Diluent on Equilibrium Phase Concentration of $\mathrm{Cr}$ Uptake on Adsorbents 
27 | International Journal of Scientific and Management Research 4(6) 14-52

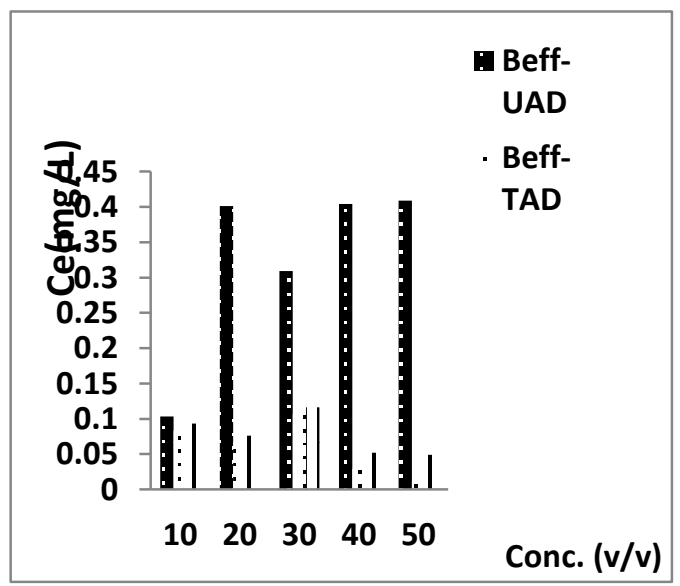

Figure 6: Effect of Diluent on Equilibrium Phase Concentration of $\mathrm{Cu}$ Uptake on Adsorbents

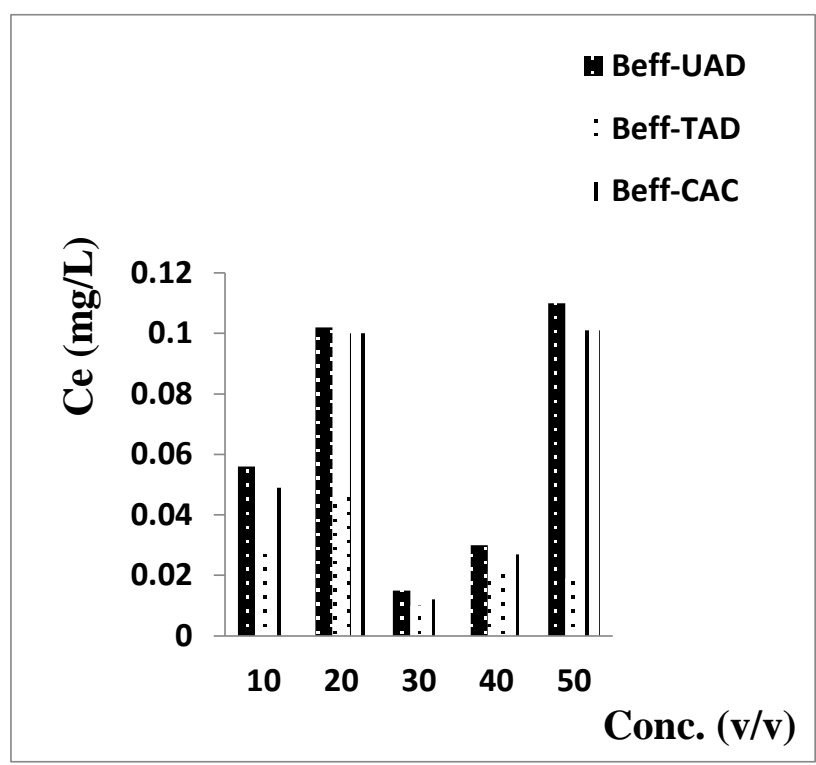

Figure 7: Effect of Diluent on Equilibrium Phase Concentration of $\mathrm{Pb}$ Uptake on Adsorbents

\section{A. Removal Efficiency (\%)}

Charts presented as Figures 8-19 showed the RE (\%) comparing the parametric factors of $\mathrm{Cd}, \mathrm{Cr}, \mathrm{Cu}$ and $\mathrm{Pb}$ adsorption onto $\mathrm{UAD}$, $\mathrm{TAD}$ and CAC.

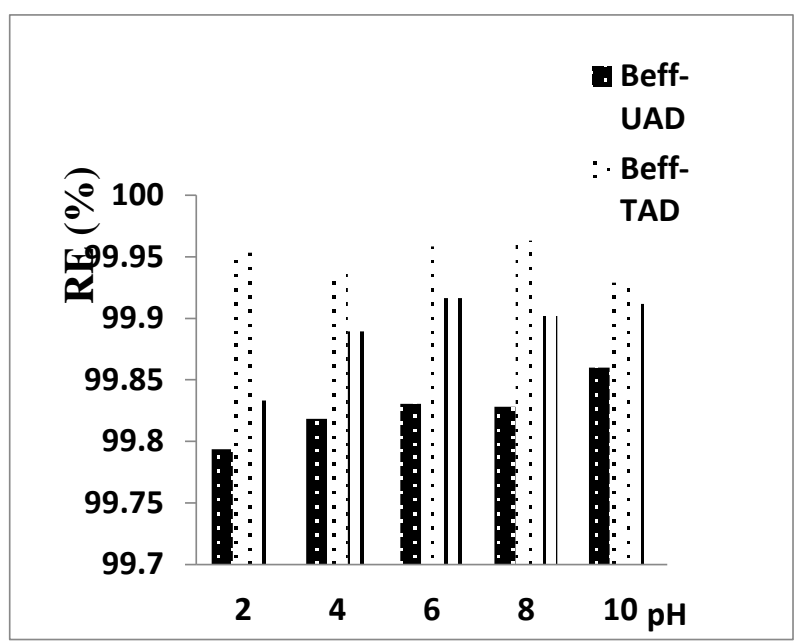

Figure 8: Effect of $\mathrm{pH}$ on Adsorption of $\mathrm{Cd}$

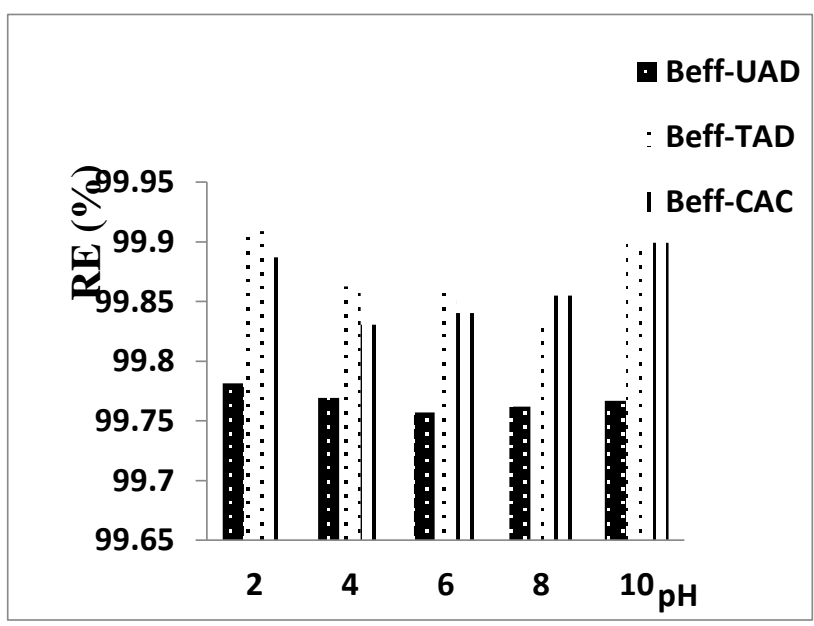

Figure 9: Effect of $\mathrm{pH}$ on Adsorption of $\mathrm{Cr}$

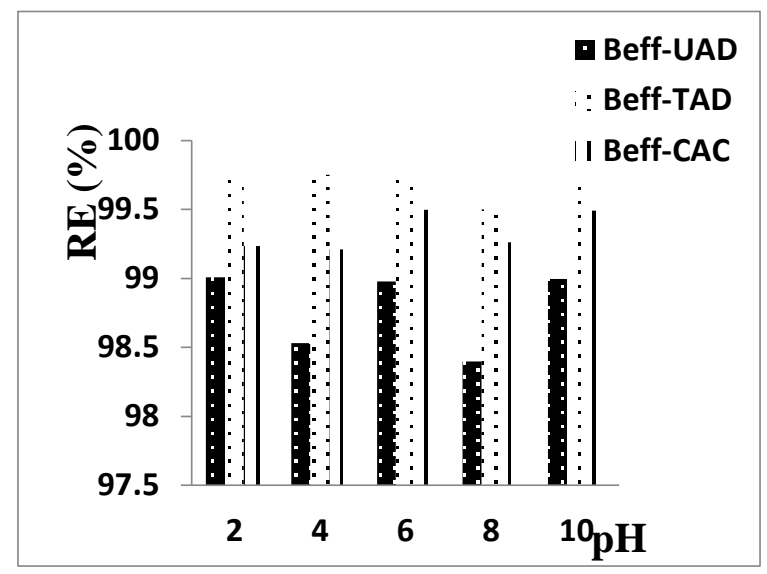

Figure 10: Effect of $\mathrm{pH}$ on Adsorption of $\mathrm{Cu}$ 
Figure 13: Effect of Time on Adsorption of $\mathrm{Cr}$

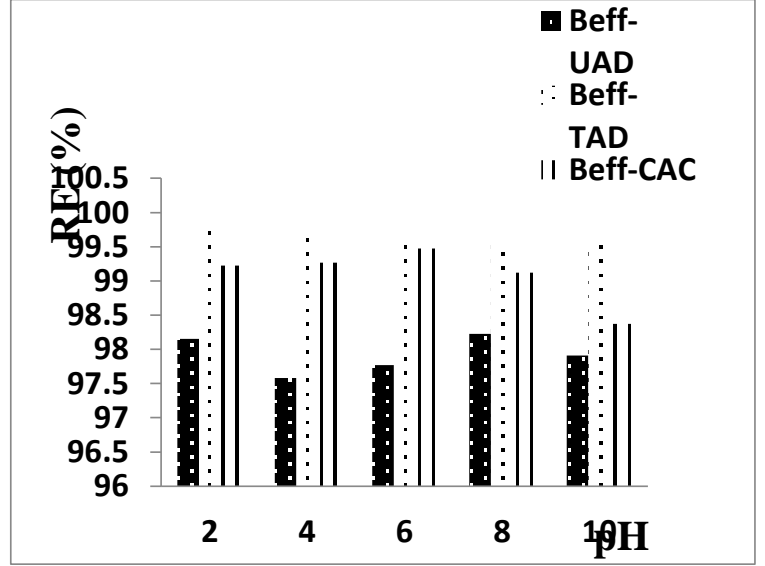

Figure 11: Effect of $\mathrm{pH}$ on Adsorption of $\mathrm{Pb}$

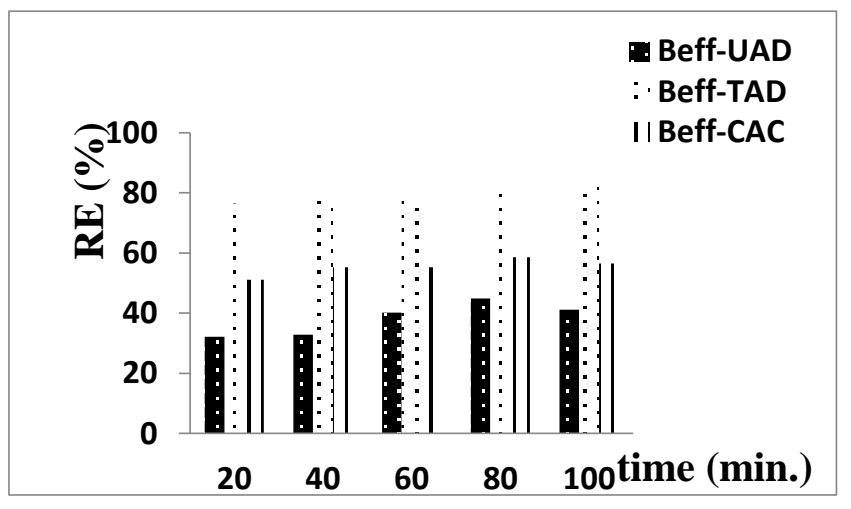

Figure 12: Effect of Time on Adsorption of $\mathrm{Cd}$

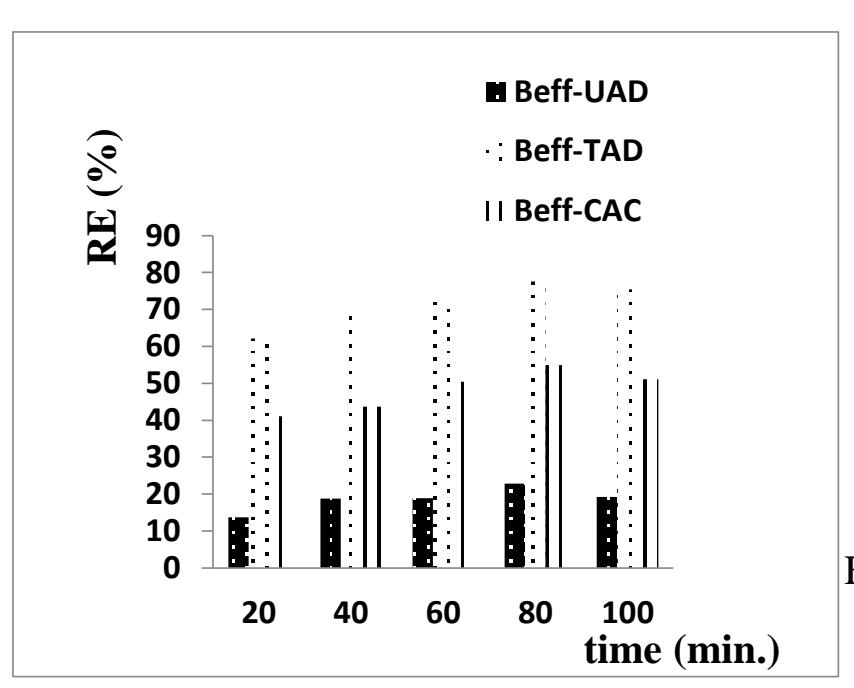

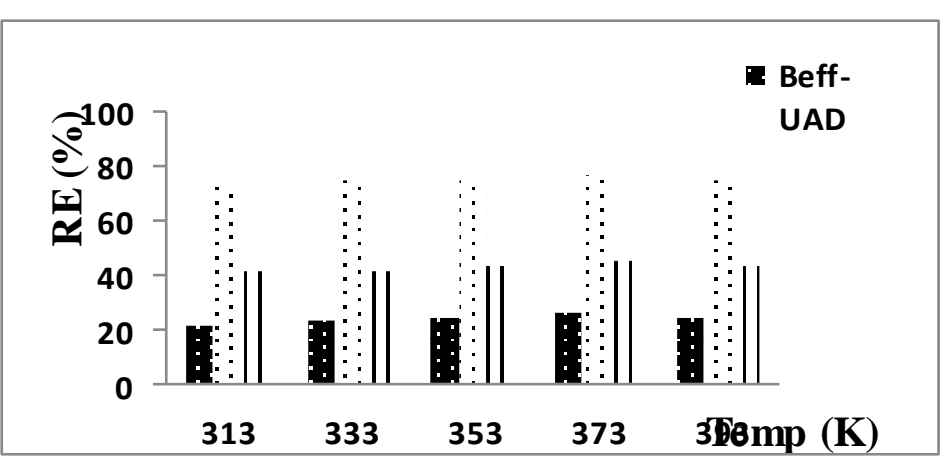

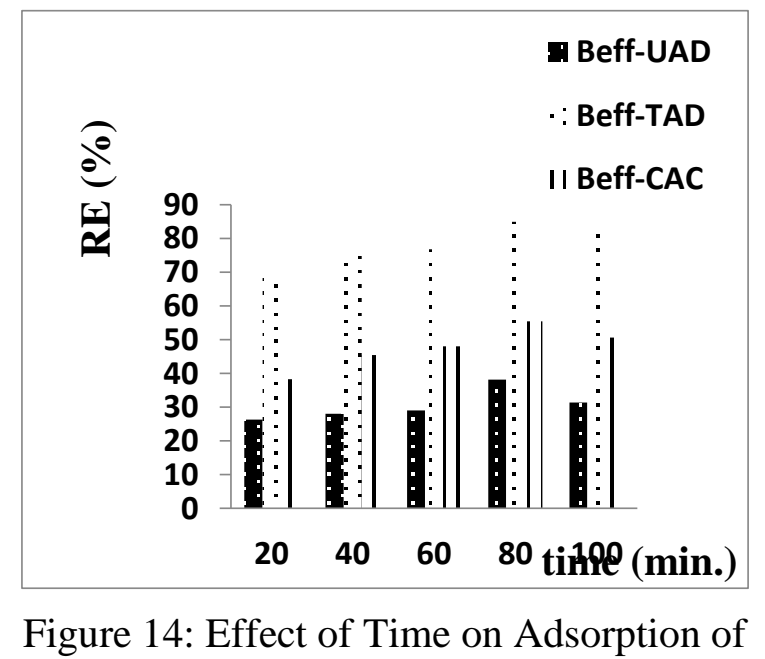

$\mathrm{Cu}$

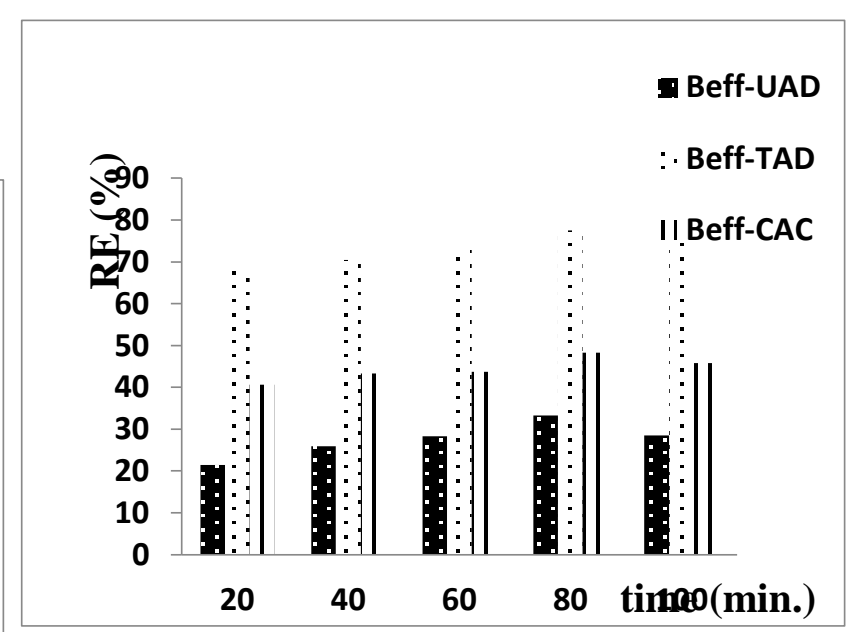

Figure 15: Effect of Time on Adsorption of $\mathrm{Pb}$ 
Figure 16: Effect of Temperature on Adsorption of $\mathrm{Cd}$
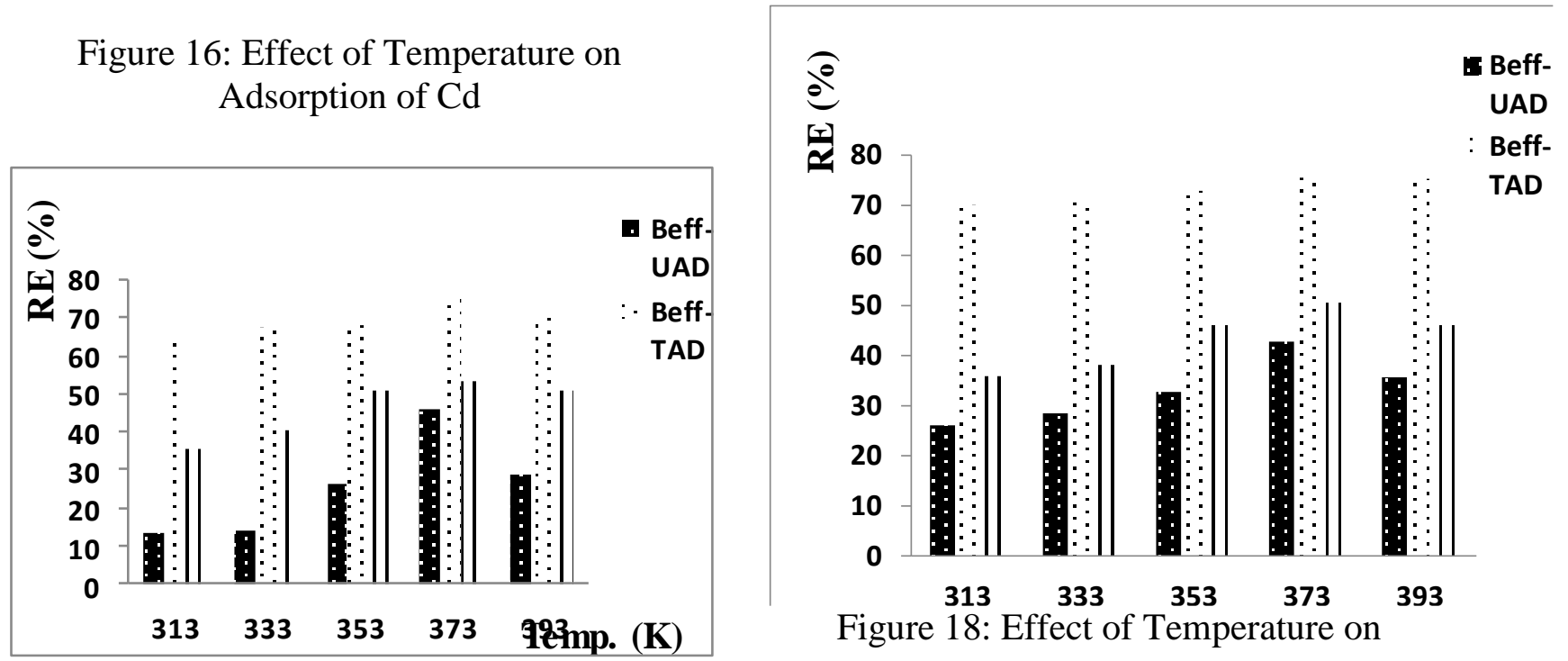

Figure 18: Effect of Temperature on

Adsorption of $\mathrm{Cu}$

Figure 17: Effect of Temperature on Adsorption of $\mathrm{Cr}$

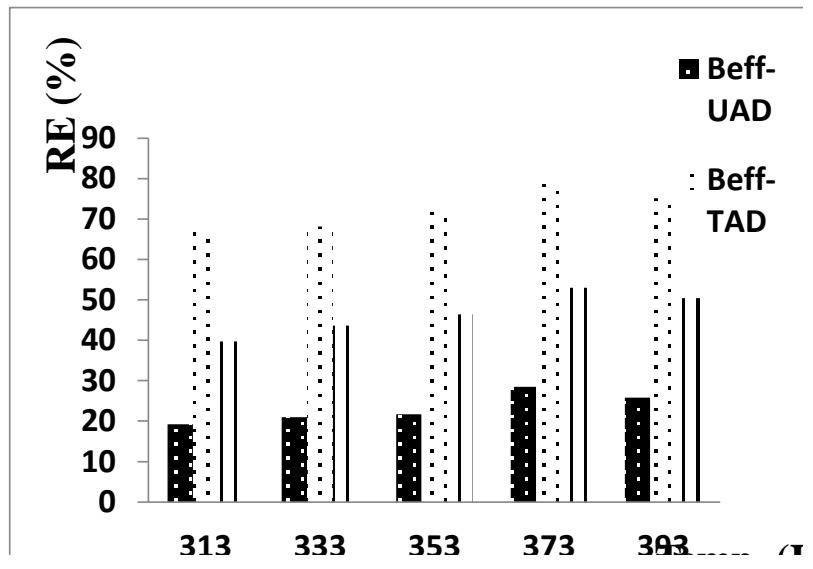

Figure 19: Effect of Temperature on $\mathrm{Pb}$

\section{Adsorption Kinetic, Diffusion Modes and Thermodynamic Studies}

Investigated kinetic studies were presented as first-order kinetic model (Figures 20-23), second-order kinetic model (Figures 24-27) and elovich kinetic model (Figures 28-31). Figures 32-39 were plots of adsorption diffusion modes (Intraparticle and Film Diffusion Modes), while Figures 40-43 represented the adsorption thermodynamic (Van't Hoff) plots.

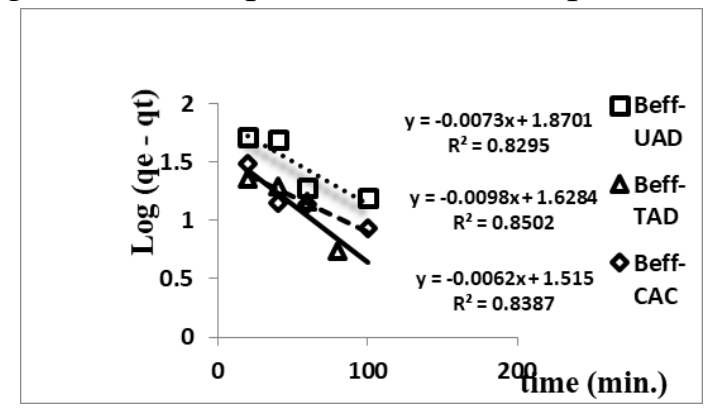

Figure 20: First-Order Kinetic Model for Cd

Adsorption 
30 | International Journal of Scientific and Management Research 4(6) 14-52

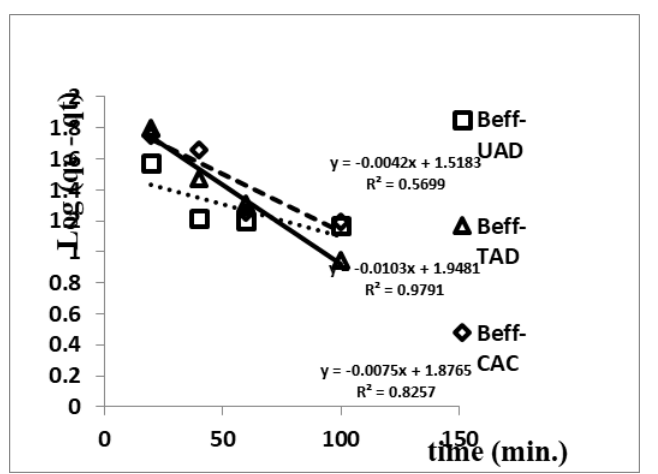

Figure 21: Fisrt-Order Kinetic Model for $\mathrm{Cr}$ Adsorption

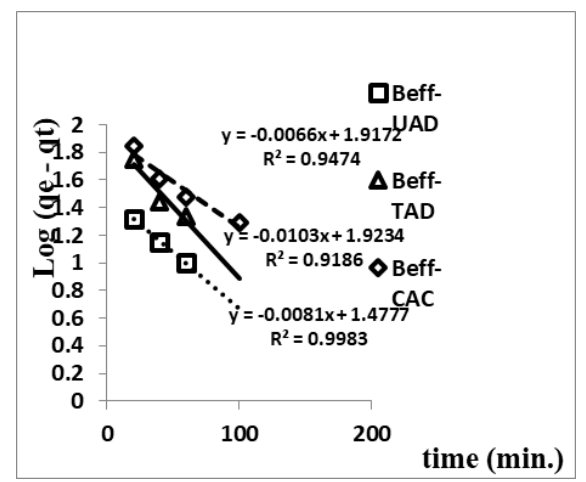

Figure 22: First-Order Kinetic Model for $\mathrm{Cu}$ Adsorption

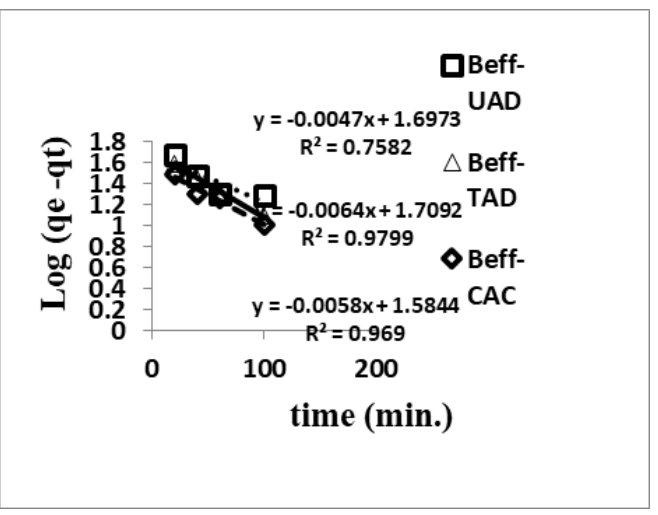

Figure 23: First-Order Kinetic Model for $\mathrm{Pb}$ Adsorption

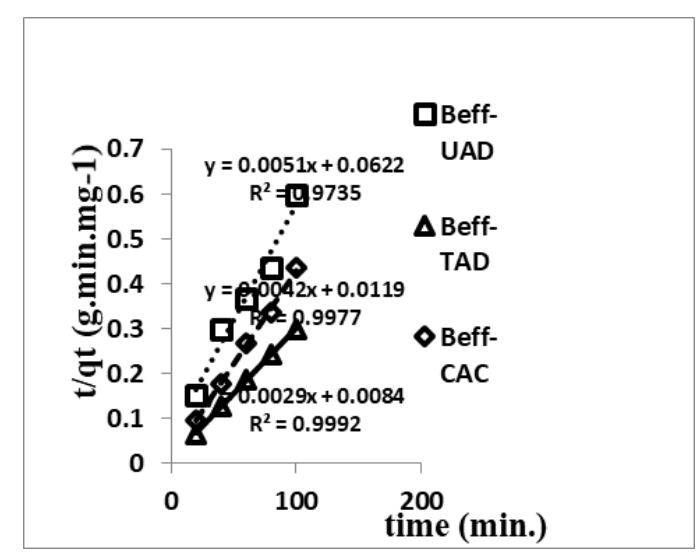

Figure 24: Second-Order Kinetic Model for

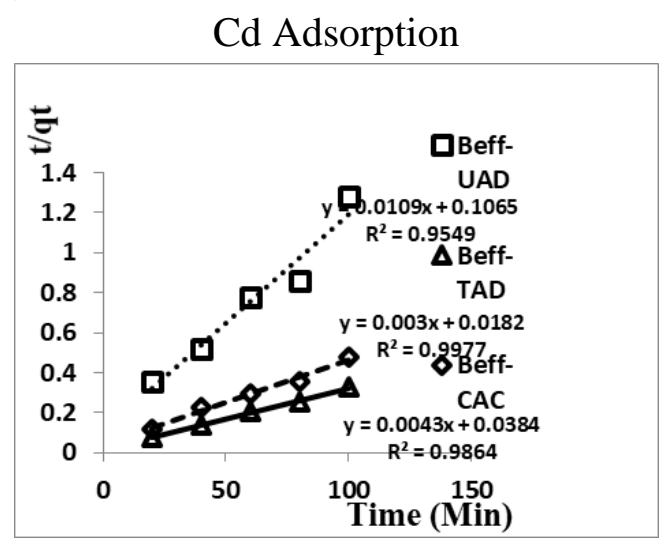

Figure 25: Second-Order Kinetic for $\mathrm{Cr}$ Adsorption

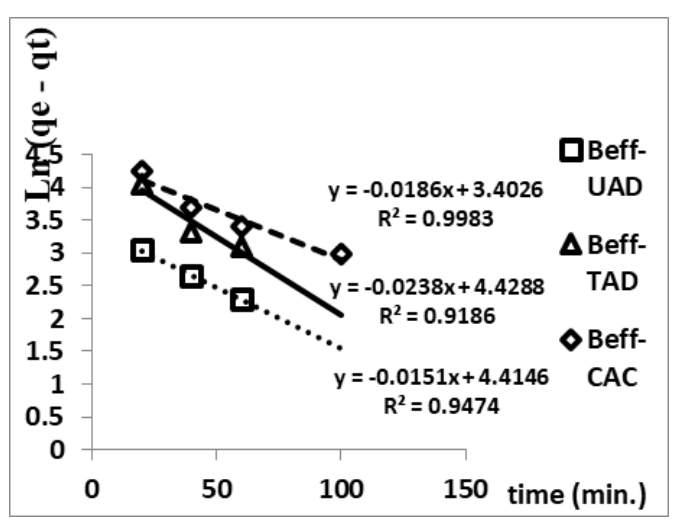

Figure 26: Second-Order Kinetic Model for $\mathrm{Cu}$ Adsorption 
31 | International Journal of Scientific and Management Research 4(6) 14-52

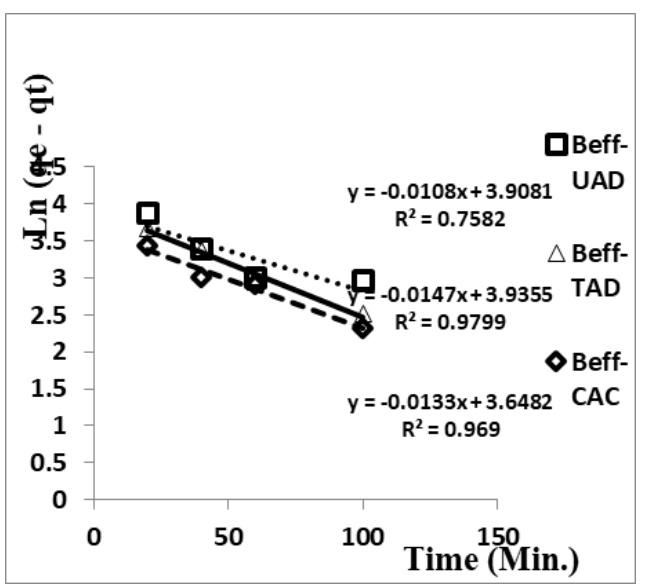

Figure 27: Second-Order Kinetic Model for $\mathrm{Pb}$ Adsorption

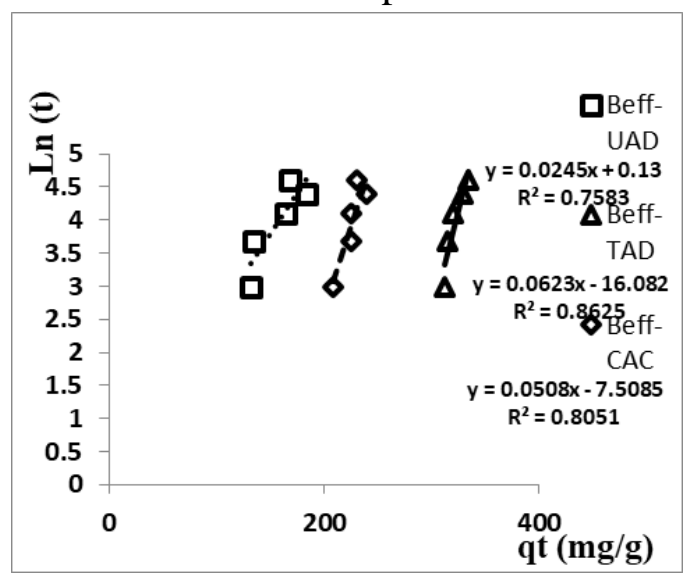

Figure 28: Elovich Kinetic Model for Cd Adsorption

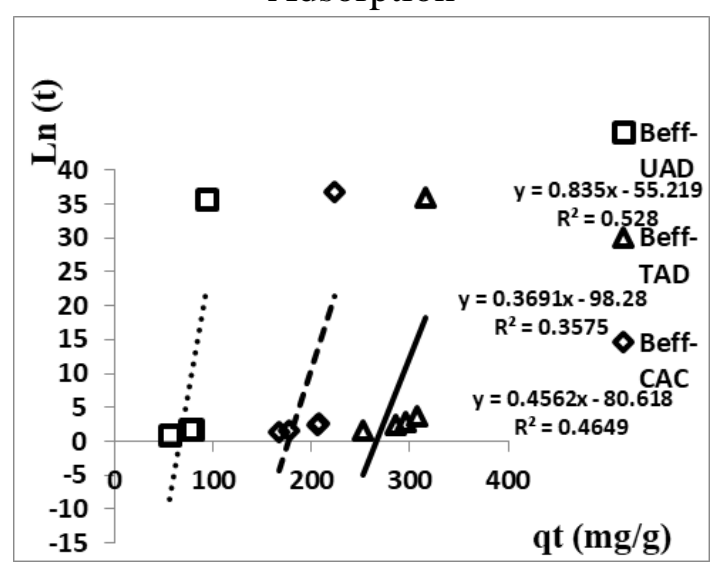

Figure 29: Elovich Kinetic Model for Cr Adsorption

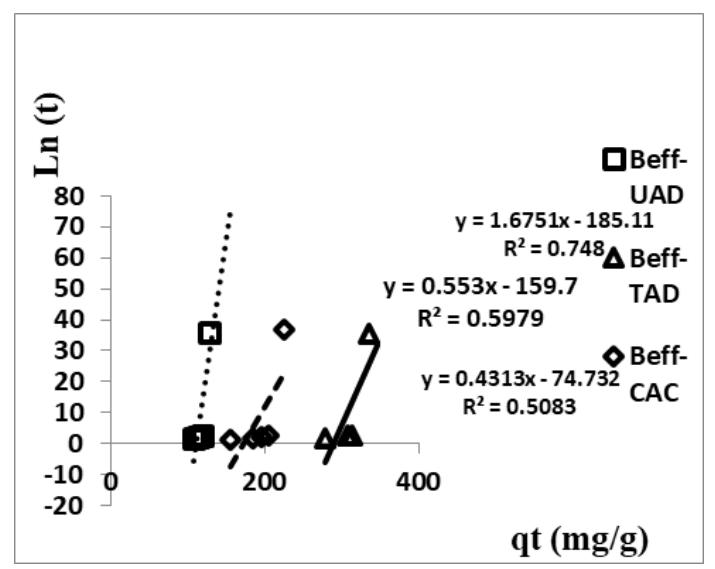

Figure 30: Elovich Kinetic Model for $\mathrm{Cu}$ Adsorption

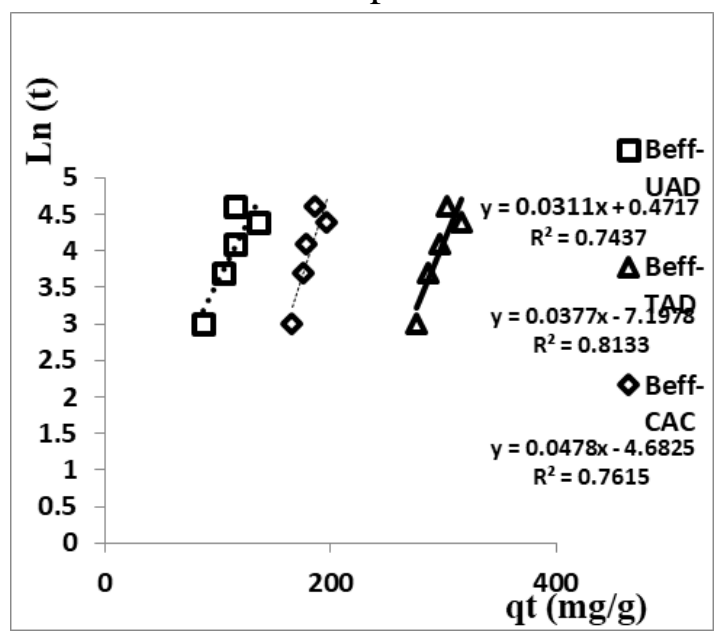

Figure 11: Elovich Kinectic Model for $\mathrm{Pb}$ Adsorption

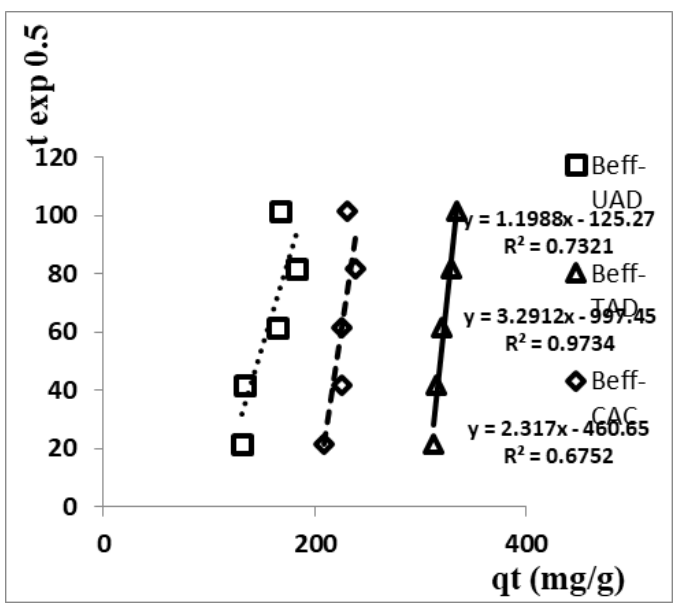

Figure 32: Intraparticle Diffusion Model for Cd Adsorption 
32 | International Journal of Scientific and Management Research 4(6) 14-52

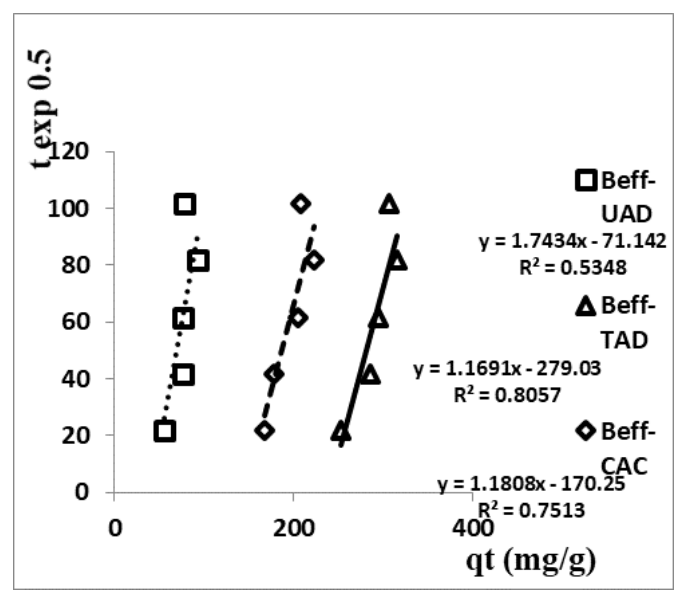

Figure 33: Intraparticle Diffusion Model for Cr Adsorption

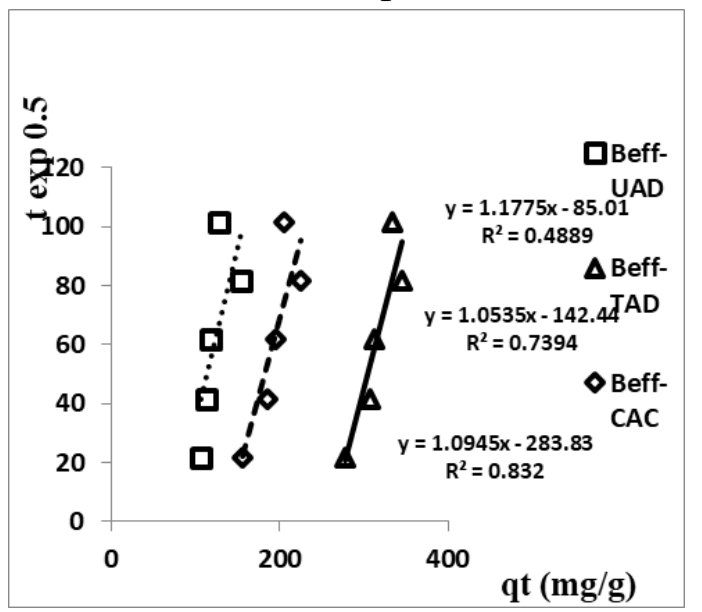

Figure 34: Intraparticle Diffusion Model for $\mathrm{Cu}$ Adsorption

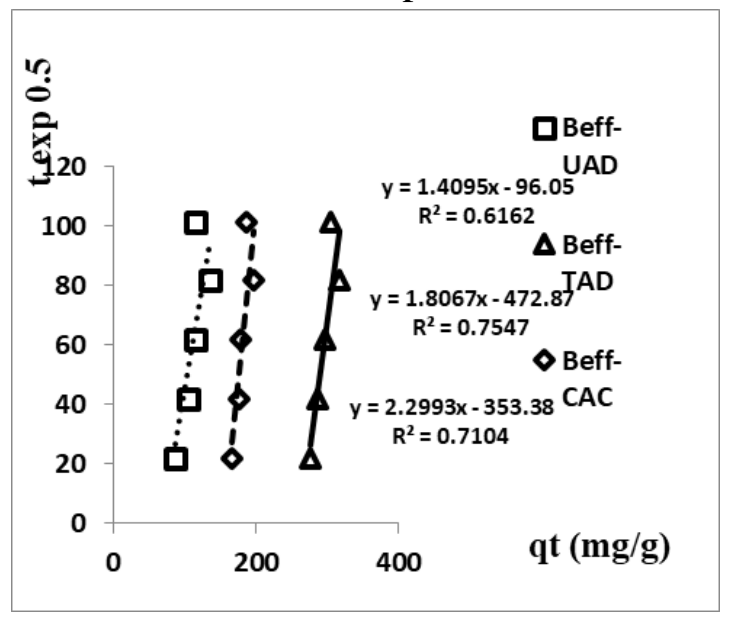

Figure 35: Intraparticle Diffusion Model for $\mathrm{Pb}$ Adsorption

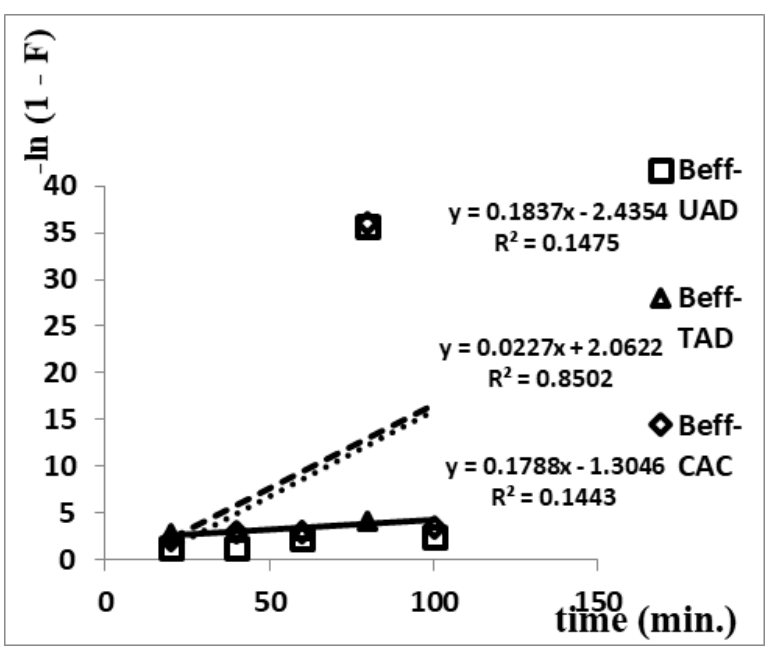

Figure 36: Film Diffusion Model for Cd

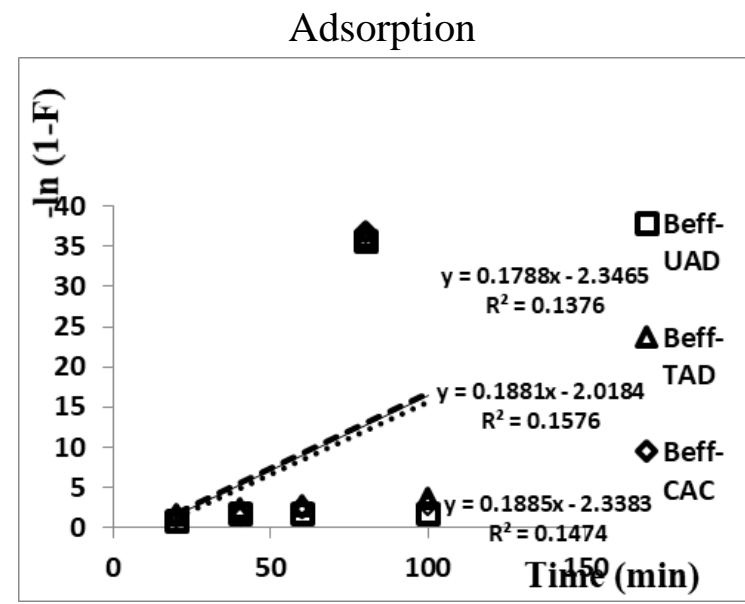

Figure 37: Film Diffusion Model for $\mathrm{Cr}$ Adsorption

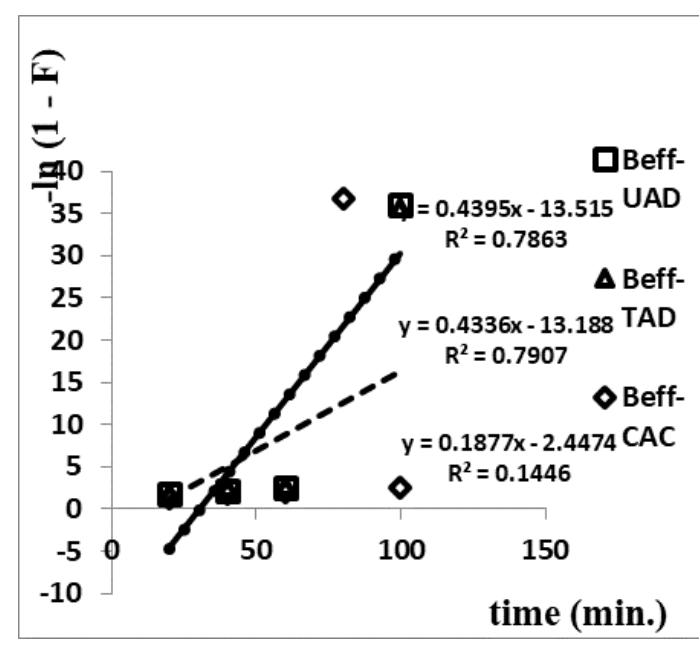

Figure 38: Film Diffusion Model for $\mathrm{Cu}$ Adsorption 
33 | International Journal of Scientific and Management Research 4(6) 14-52

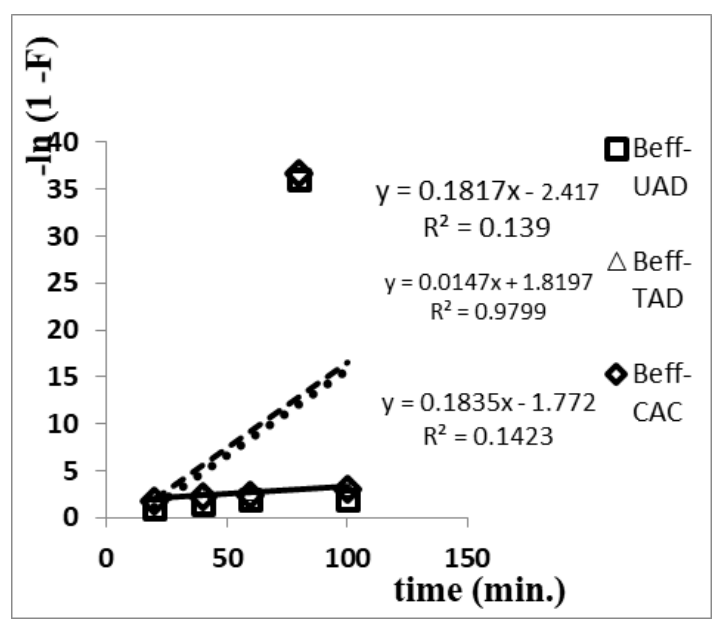

Figure 39: Film Diffusion Model for $\mathrm{Pb}$ Adsorption

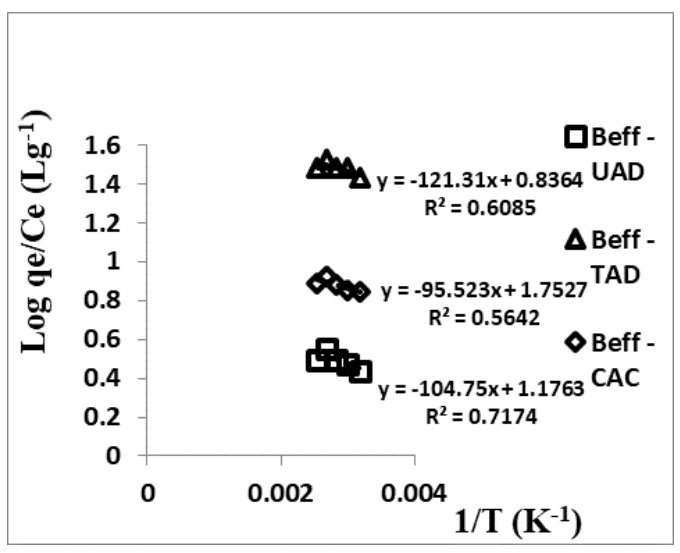

Figure 40: Van't Holf Model for Cd

Adsorption

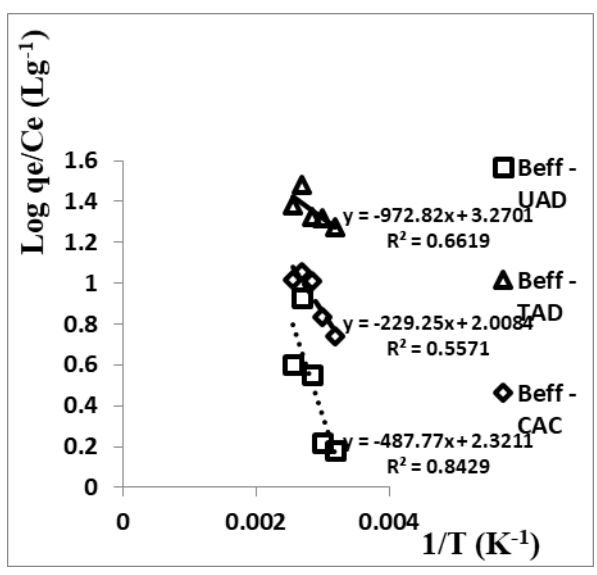

Figure 41: Van't Holf Model for Cr Adsorption

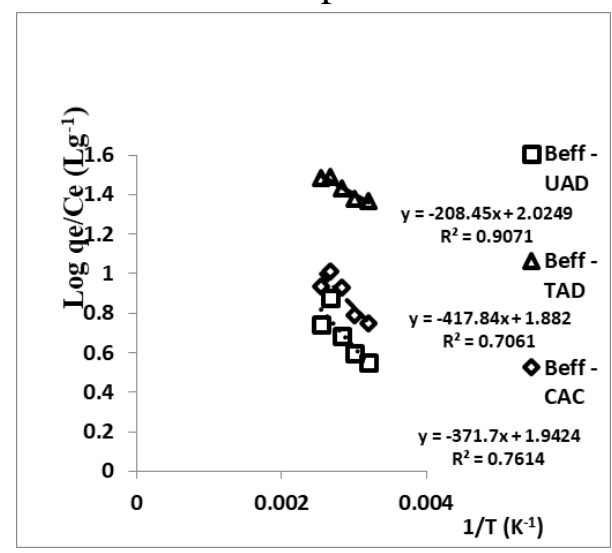

Figure 22: Van't Holf Model for $\mathrm{Cu}$ Adsorption

Table 6: First-order kinetic Studies Experimental Constants for Metals onto Activated Carbon

\begin{tabular}{|c|c|c|c|c|c|}
\hline \multirow[t]{2}{*}{ ELEMENT } & \multirow[t]{2}{*}{ EXPERIMENT } & \multicolumn{4}{|c|}{ CONSTANTS } \\
\hline & & $\mathbf{R}^{2}$ & qt Cal & qt Exp & $\mathbf{K}_{1}$ \\
\hline \multirow[t]{3}{*}{ Cadmium } & $\mathrm{B}_{\mathrm{eff}}-\mathrm{UAD}$ & 0.8295 & 0.2719 & 183.05 & 0.0168 \\
\hline & $\mathrm{B}_{\mathrm{eff}-\mathrm{TAD}}$ & 0.8502 & 0.2118 & 334.20 & 0.0226 \\
\hline & $\mathrm{B}_{\mathrm{eff}}-\mathrm{CAC}$ & 0.8387 & 0.181 & 239.80 & 0.0143 \\
\hline \multirow[t]{3}{*}{ Chromium } & $B_{\mathrm{eff}}-\mathrm{UAD}$ & 0.5699 & 0.1814 & 093.00 & 0.0097 \\
\hline & $\mathrm{B}_{\mathrm{eff}}-\mathrm{TAD}$ & 0.9791 & 0.2896 & 315.79 & 0.0237 \\
\hline & $\mathrm{B}_{\mathrm{eff}-\mathrm{CAC}}$ & 0.8257 & 0.2733 & 223.60 & 0.0173 \\
\hline \multirow[t]{3}{*}{ Copper } & $\mathrm{B}_{\mathrm{eff}}-\mathrm{UAD}$ & 0.9474 & 0.2827 & 128.09 & 0.0152 \\
\hline & $\mathrm{B}_{\mathrm{eff}}-\mathrm{TAD}$ & 0.9186 & 0.2841 & 334.54 & 0.0237 \\
\hline & $\mathrm{B}_{\mathrm{eff}}-\mathrm{CAC}$ & 0.9983 & 0.1696 & 225.70 & 0.0187 \\
\hline \multirow[t]{2}{*}{ Lead } & $\mathrm{B}_{\mathrm{eff}}-\mathrm{UAD}$ & 0.7582 & 0.2298 & 135.53 & 0.0108 \\
\hline & $\mathrm{B}_{\mathrm{eff}}-\mathrm{TAD}$ & 0.9799 & 0.2328 & 315.84 & 0.0147 \\
\hline
\end{tabular}




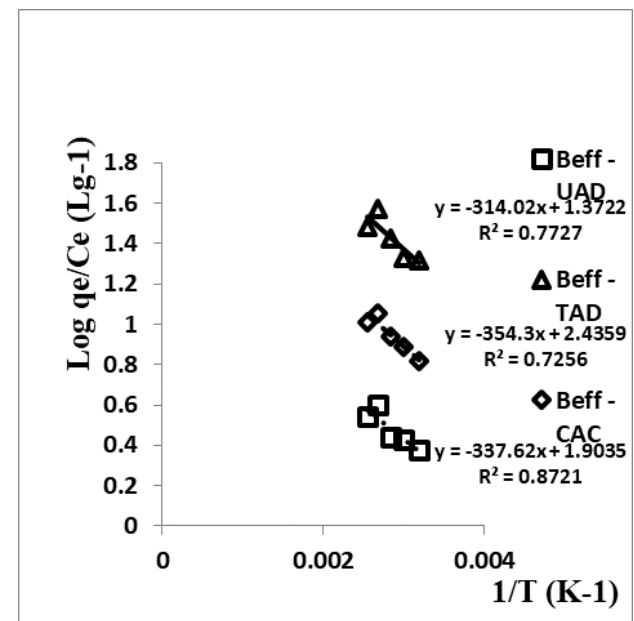

Figure 43: Van't Holf Model for Pb Adsorption

Table 7: Second-order Kinetics Studies Experimental Constants for Metals onto Activated Carbon

\begin{tabular}{|c|c|c|c|c|c|}
\hline \multirow[t]{2}{*}{ ELEMENT } & \multirow[t]{2}{*}{ EXPERIMENT } & \multicolumn{4}{|c|}{ CONSTANTS } \\
\hline & & $\mathbf{R 2}$ & qt Cal & qt Exp & K2 \\
\hline \multirow[t]{3}{*}{ Cadmium } & Beff-UAD & 0.9735 & 196.0784 & 183.05 & 0.0004 \\
\hline & Beff-TAD & 0.8625 & 238.0952 & 334.20 & 0.0015 \\
\hline & Beff-CAC & 0.9992 & 344.8276 & 238.80 & 0.0010 \\
\hline \multirow[t]{3}{*}{ Chromium } & Beff-UAD & 0.9549 & 091.7431 & 093.00 & 0.0011 \\
\hline & Beff-TAD & 0.9977 & 333.3333 & 315.79 & 0.0005 \\
\hline & Beff-CAC & 0.9864 & 232.5581 & 223.60 & 26.0417 \\
\hline \multirow[t]{3}{*}{ Copper } & Beff-UAD & 0.9983 & 53.7634 & 128.09 & 0.0001 \\
\hline & Beff-TAD & 0.9186 & 42.0168 & 334.54 & 0.0001 \\
\hline & Beff-CAC & 0.9474 & 66.2252 & 225.70 & 0.0001 \\
\hline \multirow[t]{3}{*}{ Lead } & Beff-UAD & 0.7582 & 92.5926 & 135.53 & \\
\hline & Beff-TAD & 0.9799 & 68.0272 & 315.84 & 0.0001 \\
\hline & Beff-CAC & 0.9690 & 75.1880 & 196.48 & 0.0001 \\
\hline
\end{tabular}

Table 8: Elovich Kinetic Studies Experimental Constants for Metals onto Activated Carbon

\begin{tabular}{lllll}
\hline ELEMENT & \multicolumn{3}{l}{ EXPERIMENT } & \multicolumn{3}{l}{ CONSTANTS } \\
\cline { 3 - 5 } & & $\mathbf{R}^{\mathbf{2}}$ & $\boldsymbol{\alpha}\left(\mathbf{m g} / \mathbf{g}^{-\mathbf{1}} \mathbf{~ m g}^{-\mathbf{1}}\right)$ & $\boldsymbol{\beta} \mathbf{( m g . \mathbf { g } ^ { \mathbf { - 1 } } )}$ \\
\hline Cadmium & B $_{\text {eff-UAD }}$ & 0.7583 & 0.3577 & 0.0245 \\
& B $_{\text {eff-TAD }}$ & 0.8625 & 4.5327 & 0.0623 \\
& B $_{\text {eff-CAC }}$ & 0.8051 & 3.9039 & 0.0508
\end{tabular}


35 | International Journal of Scientific and Management Research 4(6) 14-52

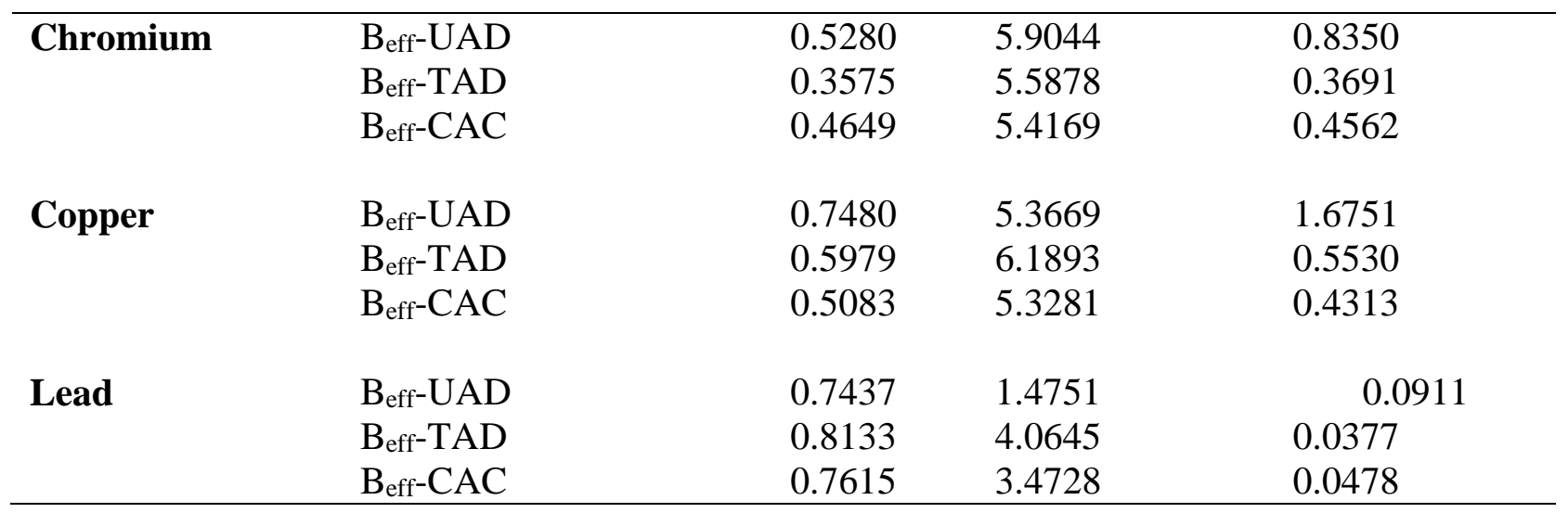

Table 9: Intraparticle Diffusion mode Experimental Constants for Metals onto Activated Carbon

\begin{tabular}{|c|c|c|c|}
\hline \multirow[t]{2}{*}{ ELEMENT } & \multirow[t]{2}{*}{ EXPERIMENT } & \multicolumn{2}{|c|}{ CONSTANTS } \\
\hline & & $\mathbf{R}^{2}$ & $\mathrm{~K}_{\mathrm{ID}}\left(\mathrm{mg} / \mathrm{g} \mathrm{min} \mathrm{m}^{1 / 2}\right)$ \\
\hline \multirow[t]{3}{*}{ Cadmium } & $\mathrm{B}_{\mathrm{eff}}-\mathrm{UAD}$ & 0.7321 & 1.1988 \\
\hline & $\mathrm{B}_{\text {eff- }}-\mathrm{TAD}$ & 0.9734 & 3.2912 \\
\hline & $\mathrm{B}_{\text {eff }}-\mathrm{CAC}$ & 0.6752 & 2.3170 \\
\hline \multirow[t]{3}{*}{ Chromium } & $\mathrm{B}_{\text {eff- }}$ UAD & 0.5348 & 1.7434 \\
\hline & $\mathrm{B}_{\mathrm{eff}}-\mathrm{TAD}$ & 0.8057 & 1.1691 \\
\hline & $\mathrm{B}_{\text {eff- }}-\mathrm{CAC}$ & 0.7513 & 1.1808 \\
\hline \multirow[t]{3}{*}{ Copper } & $\mathrm{B}_{\text {eff- }}-\mathrm{UAD}$ & 0.4889 & 1.1775 \\
\hline & $\mathrm{B}_{\mathrm{eff}}-\mathrm{TAD}$ & 0.7394 & 1.0535 \\
\hline & Beff-CAC & 0.8320 & 1.0945 \\
\hline \multirow[t]{3}{*}{ Lead } & $\mathrm{B}_{\mathrm{eff}}-\mathrm{UAD}$ & 0.6162 & 1.4095 \\
\hline & $\mathrm{B}_{\mathrm{eff}}-\mathrm{TAD}$ & 0.7547 & 1.8067 \\
\hline & $\mathrm{B}_{\mathrm{eff}}-\mathrm{CAC}$ & 0.7104 & 2.2993 \\
\hline
\end{tabular}

Table 10: Film Diffusion Mode Experimental Constants for Metals onto Activated Carbon

\begin{tabular}{|c|c|c|c|}
\hline \multirow[t]{2}{*}{ ELEMENT } & \multirow[t]{2}{*}{ EXPERIMENT } & \multicolumn{2}{|c|}{ CONSTANTS } \\
\hline & & $\mathbf{R}^{2}$ & $K_{F D}\left(L^{2} T^{-1}\right)$ \\
\hline \multirow[t]{3}{*}{ Cadmium } & $\mathrm{B}_{\mathrm{eff}}-\mathrm{UAD}$ & 0.1475 & 0.1837 \\
\hline & $\mathrm{B}_{\mathrm{eff}}-\mathrm{TAD}$ & 0.8502 & 0.0227 \\
\hline & $\mathrm{B}_{\text {eff- }}-\mathrm{CAC}$ & 0.1443 & 0.1788 \\
\hline \multirow[t]{2}{*}{ Chromium } & $\mathrm{B}_{\mathrm{eff}}-\mathrm{UAD}$ & 0.1376 & 0.1788 \\
\hline & $\mathrm{B}_{\mathrm{eff}}-\mathrm{TAD}$ & 0.1576 & 0.1881 \\
\hline
\end{tabular}


36 | International Journal of Scientific and Management Research 4(6) 14-52

\begin{tabular}{|c|c|c|c|}
\hline & $\mathrm{B}_{\text {eff }}-\mathrm{CAC}$ & 0.1474 & 0.1885 \\
\hline Copper & $\begin{array}{l}\mathrm{B}_{\text {eff- }} \text { UAD } \\
\text { B }_{\text {eff- }}-\mathrm{TAD} \\
\mathrm{B}_{\text {eff- }}-\mathrm{CAC}\end{array}$ & $\begin{array}{l}0.7863 \\
0.7907 \\
0.1446\end{array}$ & $\begin{array}{l}0.4395 \\
0.4336 \\
0.1877\end{array}$ \\
\hline Lead & $\begin{array}{l}\mathrm{B}_{\text {eff- }}-\mathrm{UAD} \\
\mathrm{B}_{\text {eff- }}-\mathrm{TAD} \\
\mathrm{B}_{\text {eff- }}-\mathrm{CAC}\end{array}$ & $\begin{array}{l}0.1390 \\
0.9799 \\
0.1423\end{array}$ & $\begin{array}{l}0.1817 \\
0.0147 \\
0.1835\end{array}$ \\
\hline
\end{tabular}

Table 11: Thermodynamic Experimental Constants for Metals Adsorption onto Activated Carbon

\begin{tabular}{|c|c|c|c|c|c|}
\hline \multirow[t]{2}{*}{ ELEMENT } & \multirow[t]{2}{*}{ EXPERIMENT } & \multicolumn{4}{|c|}{ CONSTANTS } \\
\hline & & $\mathbf{R}^{2}$ & $\begin{array}{l}\Delta \mathbf{H}(\mathbf{k j} / \\
\mathrm{mol})\end{array}$ & $\Delta S(\mathbf{k j} / \mathbf{m o l})$ & $\Delta G(k j / m o l . k)$ \\
\hline \multirow[t]{3}{*}{ Cadmium } & $\mathrm{B}_{\mathrm{eff}}-\mathrm{UAD}$ & 0.6085 & 2322.74 & 16.0147 & 2306.7253 \\
\hline & $\mathrm{B}_{\mathrm{eff}}-\mathrm{TAD}$ & 0.5642 & 1828.99 & 33.5592 & 1795.4308 \\
\hline & $\mathrm{B}_{\mathrm{eff}}-\mathrm{CAC}$ & 0.7174 & 2005.66 & 22.5228 & 1983.1372 \\
\hline \multirow[t]{3}{*}{ Chromium } & $B_{\text {eff-UAD }}$ & 0.6619 & 18626.72 & 62.6131 & 18564.106 \\
\hline & $\mathrm{B}_{\mathrm{eff}}-\mathrm{TAD}$ & 0.5571 & 4389.48 & 38.4551 & 4351.0249 \\
\hline & $\mathrm{B}_{\mathrm{eff}}-\mathrm{CAC}$ & 0.8429 & 9339.40 & 44.4424 & 9294.9576 \\
\hline \multirow[t]{3}{*}{ Copper } & $\mathrm{B}_{\mathrm{eff}}-\mathrm{UAD}$ & 0.9071 & 3991.22 & 38.7710 & 3952.4490 \\
\hline & $\mathrm{B}_{\mathrm{eff}}-\mathrm{TAD}$ & 0.7061 & 8000.44 & 36.0349 & 7964.4051 \\
\hline & $\mathrm{B}_{\mathrm{eff}}-\mathrm{CAC}$ & 0.7614 & 7116.99 & 37.1914 & 7079.7986 \\
\hline \multirow[t]{3}{*}{ Lead } & $\mathrm{B}_{\mathrm{eff}}-\mathrm{UAD}$ & 0.7727 & 6012.59 & 26.2737 & 5986.3163 \\
\hline & $\mathrm{B}_{\mathrm{eff}}-\mathrm{TAD}$ & 0.7256 & 6783.83 & 46.6405 & 6737.1895 \\
\hline & $\mathrm{B}_{\mathrm{eff}-\mathrm{CAC}}$ & 0.8721 & 643.73 & 36.4466 & 607.28340 \\
\hline
\end{tabular}

Comparative RE(\%) of Metals Beff-UAD, TAD \& CAC at $95 \%$ Confidence Interval

UAD F-Statistic of 16.148 at $\mathrm{p}=0.000$ shows that there is a significant difference, TAD FStatistic of 2.734 at $p=0.078$ shows that there is no significant difference (Hence, there is no need for Post - Hoc test) and CAC F-Statistic of 4.890 at $p=0.013$ shows that there is a significant difference in the four elements namely $\mathrm{Cd}, \mathrm{Cr}, \mathrm{Cu} \& \mathrm{~Pb}$.

Table 12: ANOVA for UAD

\begin{tabular}{|c|c|c|c|c|c|}
\hline & Sum of Squares & Df & Mean Square & $\mathrm{F}$ & Sig. \\
\hline Between & 984.711 & 3 & 328.237 & 16.148 & .000 \\
\hline Groups & & & & & \\
\hline Within & 325.227 & 16 & 20.327 & & \\
\hline Groups & & & & & \\
\hline
\end{tabular}


37 | International Journal of Scientific and Management Research 4(6) 14-52

Total 1309.938

19

Table 13: Post Hoc Test for UAD using Student-Newman-Keuls ${ }^{\mathrm{a}}$ (S-N-K)

\begin{tabular}{|c|c|c|c|c|}
\hline \multirow[t]{2}{*}{ Element } & \multirow{2}{*}{$\mathrm{N}$} & \multicolumn{3}{|c|}{ Subset for alpha $=0.05$} \\
\hline & & 1 & 2 & 3 \\
\hline $\mathrm{Cd}$ & 5 & & & 38.2906 \\
\hline $\mathrm{Cr}$ & 5 & 18.7042 & & \\
\hline $\mathrm{Cu}$ & 5 & & 30.5880 & \\
\hline $\mathrm{Pb}$ & 5 & & 27.4758 & \\
\hline Sig. & & 1.000 & .291 & 1.000 \\
\hline
\end{tabular}

Means for groups in homogeneous subsets are displayed.

a. Uses Harmonic Mean Sample Size $=5.000$.

Table 14: ANOVA for TAD

\begin{tabular}{cccccc}
\hline & Sum of Squares & Df & Mean Square & F & Sig. \\
\hline Between Groups & 198.489 & 3 & 66.163 & 2.734 & .078 \\
Within Groups & 387.196 & 16 & 24.200 & & \\
Total & 585.685 & 19 & & & \\
\hline
\end{tabular}

Table 15: Post Hoc Test for TAD using Student-Newman-Keuls ${ }^{\mathrm{a}}(\mathrm{S}-\mathrm{N}-\mathrm{K})$

\begin{tabular}{ccc}
\hline Element & $\mathrm{N}$ & Subset for alpha $=0.05$ \\
\cline { 3 - 3 } & & 1 \\
$\mathrm{Cd}$ & 5 & 79.0242 \\
$\mathrm{Cr}$ & 5 & 71.5638 \\
$\mathrm{Cu}$ & 5 & 77.5166 \\
$\mathrm{~Pb}$ & 5 & 72.6534 \\
$\mathrm{Sig}$ & & .118 \\
\hline
\end{tabular}

Means for groups in homogeneous subsets are displayed.

Table 16: ANOVA for CAC

a. Uses Harmonic Mean Sample Size $=5.000$.

\begin{tabular}{cccccc}
\hline & Sum of Squares & Df & Mean Square & F & Sig. \\
\hline Between Groups & 324.069 & 3 & 108.023 & 14.890 & .013 \\
Within Groups & 353.451 & 16 & 22.091 & & \\
Total & 677.520 & 19 & & & \\
\hline
\end{tabular}

Table 17: Post Hoc Test for CAC using Student-Newman-Keuls ${ }^{\mathrm{a}}$ (S-N-K)

\begin{tabular}{cccc}
\hline \multirow{2}{*}{ Element } & $\mathrm{N}$ & \multicolumn{2}{c}{ Subset for alpha $=0.05$} \\
\cline { 3 - 4 } & 5 & & 2 \\
$\mathrm{Cd}$ & 5 & 48.2284 & 55.3574 \\
$\mathrm{Cr}$ & &
\end{tabular}


38 | International Journal of Scientific and Management Research 4(6) 14-52

$\begin{array}{lll}\mathrm{Cu} & 5 & 47.5750\end{array}$

$\mathrm{Pb} \quad 5 \quad 44.3270$

Sig. $\quad .409$

Means for groups in homogeneous subsets are displayed.

a. Uses Harmonic Mean Sample Size $=5.000$.

\section{Discussions}

\section{Physical Examination of Sampling Site}

a. Point of effluent discharge

b. Surrounding point of impact

The physical examination showed that the effluent (Plate 2) has a high pollution density with the brownish colouration of effluent with distinct foul odour, microbial activities in the surroundings. Similar report was given by Krishanamoorthi et al., (2009).

\section{Physico-chemical Properties of Brewery Effluent}

\section{$p H$}

$\mathrm{pH}$ value of the brewery effluent discharge falls within the acceptable discharge limits of NESREA and WHO regulatory Standards, the $\mathrm{pH}$ value of 6.0 to 9.0. Higher acceptance is given to high $\mathrm{pH}$ values as though the stricter limit are monitored, since carbon dioxide from atmosphere or biological processes in healthy, surface water tends to lower the $\mathrm{pH}$ levels completely to neutral conditions. If the $\mathrm{pH}$ value of the surface water drifts off the range of 6.57.5 , sensitive aquatic organisms' lives may be lost. Metals tend to stay insoluble or more inert, and hydrogen sulphide evolution is controlled. As biological processes are introduced into the treatment, the $\mathrm{pH}$ is reduced to a more neutral condition by carbon dioxide. Uptake processes for metals can also be engaged in treatment plants. However, some of the metals has primary form ( $\mathrm{Cr}$ (III) is the primary form of $\mathrm{Cr}$ ) that is retained by sorption process. The kinetics of the primary form metal sorption is often high in clay, sand and soil containing $\mathrm{Fe}$ and manganese oxide. For instance, a study of a laboratory shows that about $90 \%$ of $\operatorname{Cr}(\mathrm{III})$ added to clay minerals and iron oxides was adsorbed within 24 hours (Richard and Bourg, 1991). Some primary forms of metals acts like positively charged ion like $\left(\mathrm{Cr}^{3+}\right)$ when adsorbing onto surfaces. As $\mathrm{pH}$ increases, surface proton are removed, increasing the attraction metal and the surface. Sorption is thereby encouraged as $\mathrm{pH}$ increases. If the soil poses a high organic content, sorption is equally encouraged, as it presents more active site for sorption to take place (Elisabeth et al., 2004

\section{Conductivity}

The conductivity of this research work has a fairly high value $(12.68 \mu \mathrm{s} / \mathrm{cm})$ as against the regulatory standards of WHO. $1200 \mu \mathrm{s} / \mathrm{cm}$ was seen but way below EPA standard of $1500 \mu \mathrm{s} / \mathrm{cm}$. the brewery effluent conductivity values increase could be as a result of concentration of ions present in the wastewater and that gives the water ability to conduct electrical current as well 
give rise to more organic matter and salinity in high concentration will give major effect on the environment

\section{Turbidity}

Turbidity value (39.3NTUs) of this effluent is way above the standard limit of NESREA with 5 NTUs and WHO of 5NTUs. This may be due to the presence of suspended and colloidal matter suck as clay, silt, finely divided organic and inorganic matter, plankton and other microscopic organism. Turbidity being the measure of clarity of a water body and its optical measurement (Bosnic et al., 2000). This is compared to the intensity of light scattered by a standard reference suspension with its records in neophelometric turbidity units (NTUs).

\section{Chemical oxygen demand (COD)}

The COD of the brewery effluent is $15.48 \mathrm{mg} / \mathrm{L}$ which is below the regulatory standard limit of NESREA (60-90 mg/L) and WHO (250 mg/L). The semi-colloidal material in suspended solids of this effluent may be way lesser in organic load of the waste water. This lower value of COD in this effluent is against the report of possibility of depletion of natural oxygen present in the effluent (Mohammed et al., 2013).

\section{Biological oxygen demand (BOD)}

The BOD is a measure of the oxygen demands of bacteria under controlled conditions, many effluents takes longer lag than the period of analysis to break down. Chemicals can be partial or significant in their broken down process. The longer lag digestion periods applies to a variety of certain retaining agents in some synthetic fat liquor, (Peter et al., 2014). This was the case in the course of this analysis. The BOD result of the analysis is $8.991(\mathrm{mg} / \mathrm{L})$ which is also below the regulatory standard of NESREA $(30-50 \mathrm{mg} / \mathrm{L})$ and WHO $(30 \mathrm{mg} / \mathrm{L})$. This is equally attributed to the less presence of colloidal suspended material in the waste water reported by Bosnic et al., (2003).

\section{Physical Characterization of Adsorbent}

Ash

The ash content of untreated activated carbon (UAD) is $12.21 \pm 0.370$ which is higher than the commercial activated carbon (CAC) $7.10 \pm 0.03$ which made it less attractive for adsorption, the ash content of treated activated carbon (TAD) is $4.22 \pm 0.60$ which is lower as against the $\mathrm{CAC}$ and that made it more favourable for high adsorption. The ash content of Commercial activated carbon (CAC) is mostly found to be $2 \%$ (Bosnic et al., 2003). This includes the bulk mineral matter after carbon, oxygen, sulphur, and volatility during combustion. The ash content for this work on untreated carbon falls out of the percentage rating to that of CAC while the treated activated carbon (TAD) is in agreement with the CAC percentage rating (Veena et al., 2012).

\section{Bulk density}

The density of granular activated carbon if loaded into its packaging with a lower limit on bulk density standard set by American Water Works Association is $0.25 \mathrm{gm} / \mathrm{ml}$ for activated 
carbon to be of practical use. The result of the bulk density value of the adsorbents are shown in Table ... $0.02 \pm 0.01\left(\mathrm{~g} / \mathrm{cm}^{3}\right)$ for Treated Adsorbent (TAD) is in agreement with values reported in literatures (Veena et al., 2012) while $0.09 \pm 0.02 \mathrm{~g} / \mathrm{cm}^{3}$ for untreated adsorbents (UAD) and $0.30 \pm 0.02\left(\mathrm{~g} / \mathrm{cm}^{3}\right)$ for Commercial Activated Carbon (CAC) which is in disagreement with the value reported by Veena et al., (2012). The bulk density was determined using the method described by Itodo et al., (2010), reduction in bulk density as in the case of treated adsorbent (TAD) is observed to have reduced, possibly due to the chemical treatment given to it during preparation.

\section{Iodine number}

Iodine number is an important factor applied to ensure the tendency of performance ratio of an activated carbon. It measures level of activities and values are reported in $\mathrm{mg} / \mathrm{g}$ (typical ranges are from $500-1200$ ). The iodine number test is used to determine the adsorption rate of iodine from an aqueous solution. It shows the extent of micro-pores and indicates for total surface area of adsorbents. Adsorbents with high iodine number performs better in removing small size particle (contaminants), while those with low iodine number performs better in removing medium sized particles (contaminants). Iodine number is the most essential factor used to characterize the efficiency of activated carbon. Higher values indicate high level of iodine number adsorption as documented by Aziz et al., (2008). From the result obtained on Table ..., untreated adsorbent (UAD) gave fairly high iodine number of 94.14 (mg/g), Treated Adsorbent (TAD) indicated a higher value of iodine number of $182.19(\mathrm{mg} / \mathrm{g})$ and commercial activated carbon (CAC) showed the least value of iodine number of 073.36 (mg/g) compared to others. This is an indication that UAD and TAD is suitable under consideration in the removal efficiency of high contaminants while CAC is for the removal efficiency of low contaminants.

\section{Moisture content}

This referred to be a measure of the amount of water in any form in a substance or adsorbent per time. Moisture content for UAD was valued at $7.08 \%$, TAD at $3.12 \%$ and CAC at $6.67 \%$.

\section{SEM Characteristics of Adsorbents}

SEM results for the adsorbents show the micrographs at various conditions, untreated adsorbents (UAD) pore size development is not too pronounced as it look so cemented with smooth surface, Treated adsorbent (TAD) and CAC show some level of resemblance with rough surfaces which is likened to an indication of pore size development. This could mean more site of adsorption of adsorbate pollutants (Niswir et al., 2013). The bright spots indicate for rough and porous surfaces of the adsorbent, and this is one of the parameters for increasing adsorption capacity (Gupta and Nayak 2011).

Comparatively, UAD indicate smooth external surface depicting micro-pores with less reactive sites (Moradi et al., 2015), while TAD and CAC indicates the presence of cave, pore and surface of adsorbents with structural formation (Gupta and Nayak 2011). This provide more reactive site that is responsible for the adsorption capacity (Moradi et al., 2015). 


\section{FTIR Analysis of Adsorbents}

Difference in functional groups like hydroxyl $(-\mathrm{OH})$, amine $(-\mathrm{NH})$, carboxulate anions (COO-) and others $(-\mathrm{C}-\mathrm{C}),(-\mathrm{C}=\mathrm{C}),(-\mathrm{C} \equiv \mathrm{C}),(-\mathrm{C}-\mathrm{N}),(-\mathrm{C}-\mathrm{H}),(-\mathrm{C}=\mathrm{O})$ have been said to be responsible for metal binding by the factor such as the quantity of sites, its accessibility, chemical state or affinity between site and metal, large pores, availability of oxygen, hydrogen content, Hydroxyl and carboxylic group on different biosorbents (Masood et al., 2009) and their importance in identification of surface functional group and their metal uptake mechanism (Kibami et al., 2014).

The FTIR analysis of adsorbent given in the Table for the FT-IR analysis of UAD, TAD and CAC (Adsorbents) in Figure the peaks at $3634.2 \mathrm{~cm}^{-1}$ and $3693.8 \mathrm{~cm}^{-1}$ within the frequency range of $4000-3500 \mathrm{~cm}^{-1}$ are as a result of stretching vibration of $\mathrm{OH}$ groups located between the center and the edge of the TAD and CAC platelets (Mohammed et al., 2010). The band at $3272.6 \mathrm{~cm}^{-1}$, $3201.8 \mathrm{~cm}^{-1}$ and $3287.5 \mathrm{~cm}^{-1}$ in the range of $3499-3000 \mathrm{~cm}^{-1}$ for UAD, TAD and CAC which indicates the presence of NH group (Ahmed et al., 2015). The band noticed at $2918.5 \mathrm{~cm}^{-1}$ and $2914.8 \mathrm{~cm}^{-1}$ for UAD and CAC in the range of $2999-2500 \mathrm{~cm}^{-1}$ is aligned to asymmetric stretches of $-\mathrm{CH}$ group from alkanes (Makeswari et al., 2016). The band of $2374.3 \mathrm{~cm}^{-1}, 2344.5 \mathrm{~cm}^{-1}$ and $2113.44 \mathrm{~cm}^{-1}$ for TAD, $2091.0 \mathrm{~cm}^{-1}$ and $2053.8 \mathrm{~cm}^{-1}$ for CAC and $2076.1 \mathrm{~cm}^{-1}$ for UAD in the frequency range of $2499-2000 \mathrm{~cm}^{-1}$ is due to $\mathrm{C}=\mathrm{O}$ stretch from esters/carboxylic acids, $\mathrm{C} \equiv \mathrm{N}$, $\mathrm{C} \equiv \mathrm{C}$ and $\mathrm{SP}^{2} \mathrm{C}-\mathrm{H}$ stretches from Nitriles, Alkynes and Aromatic compounds respectively (Abdus-Salam and Buhari 2014, El-Dars et al., 2016). The band noticed at $1997.9 \mathrm{~cm}^{-1}$, $1912.1 \mathrm{~cm}^{-1}$ is an indication of impurity that may arise during preparation of TAD (Aroke et al., 2013). The peak at $1774.2 \mathrm{~cm}-1$ for $\mathrm{TAD}$ is responsible for $\mathrm{C}=\mathrm{O}$ stretch from ketones/Esters, $1722.0 \mathrm{~cm}^{-1}$ for $\mathrm{UAD}$ is responsible for $\mathrm{C}=\mathrm{O}$ stretch from Aldehydes and $1703.4 \mathrm{~cm}^{-1}$ for $\mathrm{CAC}$ is responsible for $\mathrm{C}=\mathrm{O}$ stretch from carboxylic acids/esters while $1636.3 \mathrm{~cm}^{-1}$ for $\mathrm{CAC}$ is attributed to $\mathrm{C}=\mathrm{C}$ stretch from Alkenes (El-Dars et al., 2016). The band $1602.8 \mathrm{~cm}^{-1}$ for UAD, $1580.4 \mathrm{~cm}^{-1}$ and $1524.5 \mathrm{~cm}^{-1}$ for $\mathrm{TAD}$ are attributed to $\mathrm{C}=\mathrm{C}$ stretch from aromatic compounds (Afaj et al., 2015). The band $1367.9 \mathrm{~cm}^{-1}, 1319.5 \mathrm{~cm}^{-1}, 1237.9 \mathrm{~cm}^{-1}$ and $1151.7 \mathrm{~cm}^{-1}$ for UAD and $1271.0 \mathrm{~cm}^{-1}$ for TAD is attributed to $\mathrm{C}-\mathrm{N}$ stretching vibration of Amines which agrees closely with frequency range 1499-1000 $\mathrm{cm}^{-1}$ (Aroke et al., 2013).

\section{Column Adsorption Studies}

Effect of pH

$\mathrm{B}_{\text {eff }}-\mathrm{UAD}$ showed highest percentage removal for $\mathrm{Cd}$ at $\mathrm{pH} 10, \mathrm{~B}_{\text {eff }}-\mathrm{TAD}$ at $\mathrm{pH} 8$ and $\mathrm{B}_{\text {eff }}$ - $\mathrm{CAC}$ at $\mathrm{pH} 6$.

$\mathrm{B}_{\text {eff }}-\mathrm{UAD}$ showed highest percentage removal for $\mathrm{Cr}$ at $\mathrm{pH} 2, \mathrm{~B}_{\text {eff }}-\mathrm{TAD}$ at $\mathrm{pH} 2$ and $\mathrm{B}_{\text {eff }}-$ $\mathrm{CAC}$ at $\mathrm{pH} 10$.

$\mathrm{B}_{\text {eff }}-\mathrm{UAD}$ showed highest percentage removal for $\mathrm{Cu}$ at $\mathrm{pH} 2, \mathrm{~B}_{\text {eff }}-\mathrm{TAD}$ at $\mathrm{pH} 4$ and $\mathrm{B}_{\text {eff }}-$ $\mathrm{CAC}$ at $\mathrm{pH} 6$

$\mathrm{B}_{\text {eff }}-\mathrm{UAD}$ showed highest percentage removal for $\mathrm{Pb}$ at $\mathrm{pH} 2, \mathrm{~B}_{\text {eff }}-\mathrm{TAD}$ at $\mathrm{pH} 2$ and $\mathrm{B}_{\text {eff }}-$ $\mathrm{CAC}$ at $\mathrm{pH} 6$ 
The removal of $\mathrm{Cd}$ ion was more at higher $\mathrm{pH}$ for UAD and TAD because, the surfaces of activated carbons are negatively charged as a result of excessive $\mathrm{OH}^{-}$ions present in the solution (Suguna et al., 2010). Consequently, electrostatic attraction between cationic metal ions and anionic surfaces of activated carbons increases the quantity of $\mathrm{Cd}$ adsorbed at maximum percentage which occurred at $\mathrm{pH}$ 6-10. The removal of $\mathrm{Cr}, \mathrm{Cu}$ and $\mathrm{Pb}$ were more at lower $\mathrm{pH}$ for UAD and TAD due to the surfaces of activated carbons that are more positively charged because of excess of $\mathrm{H}^{+}$ions in the solution (Karichappan et al., 2014). The electrostatic repulsion between metal ions and the surfaces of the adsorbents decreases the amount of metal taken.

\section{Effect of time}

The data measures the effect of contact time (min.) on the column absorption of metal ions indicated that variation in percentage removal efficiency of metal ions with elapsed time has been shown on Table 4-7 and it is evident from their figures 11-14.

$\mathrm{B}_{\text {eff }}-\mathrm{UAD}$ for $\mathrm{Cd}$ gave highest percentage removal of $44.952 \%$ at $80 \mathrm{~min}, \mathrm{~B}_{\text {eff }}-\mathrm{TAD}$ gave the highest percentage removal of $82 \%$ at $100 \mathrm{~min}$ and $\mathrm{B}_{\text {eff }}-\mathrm{CAC}$ gave 58.643 at $80 \mathrm{~min}$.

$\mathrm{B}_{\text {eff }}$-UAD for $\mathrm{Cr}$ gave highest percentage removal of $22.838 \%$ at $80 \mathrm{~min}, \mathrm{~B}_{\text {eff }}$-TAD gave highest percentage removal of $77.550 \%$ at $80 \mathrm{~min}$ and $\mathrm{B}_{\text {eff }}-\mathrm{CAC}$ gave $54.910 \%$ at $80 \mathrm{~min}$.

$\mathrm{B}_{\text {eff }}-\mathrm{UAD}$ for $\mathrm{Cu}$ gave the highest percentage removal of $38.138 \%$ at $80 \mathrm{~min}, \mathrm{~B}_{\text {eff }}-\mathrm{TAD}$ gave $84.968 \%$ at $80 \mathrm{~min}$ and Beff-CAC gave $55.426 \%$ at $80 \mathrm{~min}$.

$\mathrm{B}_{\text {eff }}-\mathrm{UAD}$ for $\mathrm{Pb}$ gave the highest percentage removal of $33.283 \%$ at $80 \mathrm{~min}, \mathrm{~B}_{\text {eff }}-\mathrm{TAD}$ gave $77.562 \%$ at $80 \mathrm{~min}$ and $\mathrm{B}_{\text {eff }}-\mathrm{CAC}$ gave $48.250 \%$ at $80 \mathrm{~min}$.

The percentage removal using TAD was the highest even more compared to CAC due to its agreement on bulk density with Veena et al., (2012) and as it recorded the highest value of iodine number compared to UAD and CAC (Itodo et al., 2010). The increase in the trend of metal removal with increasing time (20-80 minutes) was achieved due to adsorbent general monolayer formation on adsorbent surfaces. Thus the removal of metal ions from aqueous solution was controlled by the transport rate of adsorbate species from exterior to interior sites of adsorbent (Veena et al., 2012).

\section{Effect of temperature}

To study the effect of temperature on metal ions removal, the experiments were carried out at temperature varying from 313 to $393 \mathrm{k}$ : it was found out that $\mathrm{B}_{\text {eff }}-\mathrm{UAD}$ for $\mathrm{Cd}$ gave highest removal percentage at $373 \mathrm{~K}(26.092 \%), \mathrm{B}_{\text {eff }}-\mathrm{TAD}$ gave at $373 \mathrm{k}(76.877 \%)$ and $\mathrm{B}_{\text {eff }}-\mathrm{CAC}$ gave at $373 \mathrm{k}(45.493 \%)$; $\mathrm{B}_{\text {eff }}-\mathrm{UAD}$ for $\mathrm{Cr}$ gave highest removal percentage at $373 \mathrm{~K}(45.942 \%), \mathrm{B}_{\text {eff }}$ TAD gave at $373 \mathrm{~K}(75.123 \%)$ and $\mathrm{B}_{\text {eff }}-\mathrm{CAC}$ gave at $373 \mathrm{~K}(53.044 \%)$; $\mathrm{B}_{\text {eff }}-\mathrm{UAD}$ for $\mathrm{Cu}$ gave highest removal percentage at $373 \mathrm{~K}(42.833 \%)$, Beff-TAD gave at $373 \mathrm{~K}(75.551 \%)$ and $\mathrm{B}_{\text {eff }}$ $\mathrm{CAC}$ gave at $373 \mathrm{~K}(50.618 \%)$; $\mathrm{B}_{\text {eff }}-\mathrm{UAD}$ for $\mathrm{Pb}$ gave highest removal percentage at $373 \mathrm{~K}(28.504 \%), \mathrm{B}_{\text {eff }}-\mathrm{TAD}$ gave at $373 \mathrm{~K}(78.957 \%)$ and $\mathrm{B}_{\text {eff }}-\mathrm{CAC}$ gave $373 \mathrm{~K}(52.100 \%)$. The highest removal percentages were recorded at $373 \mathrm{~K}$ for the metal ions; the removal of metals with temperatures increased the mobility of the ions of the effluent and yielded a swelling impact with the interior structure of adsorbent, thus allowing the large molecules of effluent to move 
deeper (Verma and Mishra, 2010). The temperature activates the level of metal by altering the molecular interactions and solubility of metals. The efficient removal of metals due to increasing temperature causes more interaction between adsorbate and adsorbent (Hiroyuki et al., 1994). Desorptions occurred at temperature 393 for all metals, as resulted decrease in percentage removal with rise in temperature caused by thermal energy as though higher temperatures induces higher mobility of adsorbate (Pandey et al., 2010).

\section{Adsorption Kinetics}

The study of adsorption mechanism describes the solute up-take level and plainly, this rate regulates the residence time of adsorbate uptake at the solid-solution interface Taha et al.,(2014), adduced that a kinetic model aids the study of adsorption rate, model the process and predict information about adsorbent/adsorbate interaction (Physisorption or chemisorptions). The kinetics of metals ions adsorption on the activated carbons were analyzed using first-order (Ho and Mckay, 1998) second-order(Ho et al., 2001), Elovich (Chien and Clayton, 1980) kinetic model (Amanda et al., 2013).

\section{First-order kinetic model}

The rate constant of adsorption was determined from first-order equation given by Langergren and Svenska (Olugbenga et al., 2010). The $\mathrm{R}^{2}$ values for this model as studied for Cd UAD (0.8295), TAD(0.8502) and CAC(0.8387); $\mathrm{Cr}-\mathrm{UAD}(0.5699), \mathrm{TAD}(0.9791)$ and $\mathrm{CAC}(0.8257)$; $\mathrm{Cu}-\mathrm{UAD}(0.9474), \mathrm{TAD}(0.9186)$ and $\mathrm{CAC}(0.9983), \operatorname{Pb}-\mathrm{UAD}(0.7582), \mathrm{TAD}(0.9799)$ and CAC(0.969). The low correlation coefficient values obtained from first-order kinetic models is not occurring exclusively unto one site per ion for $\mathrm{Cd}$ and $\mathrm{Cr}$ (Nuhoglu and Malkoc, 2009). However, the high correlation coefficient value obtained from the first-order kinetic models for $\mathrm{Cu}$ shows indication of their exclusive occurrence suitable application for kinetic adsorption unto one site per ion. Moreover, it was observed that the correlation coefficient value for $\mathrm{Pb}$ was found to have a close agreement for both first and second order kinetic models for the derived adsorbents and commercial activated carbon (CAC) implicates that either model is as suitable for describing the rate of $\mathrm{Pb}$ uptake by adsorbents (Zawani et al., 2009), qt (exp) and qt(Cal) tested did not show any close agreement when compared to second-order constants.

\section{Second-order kinetics model}

The coefficient of regression suggested the applicability for second-order kinetic model for Cd-UAD (0.9735), TAD (0.9977) and CAC (0.9992); Cr-UAD (0.9549), TAD (0.9977), CAC (0.9864); Cu-UAD (0.9983), TAD (0.9186) and CAC (0.9474); Pb-UAD (0.7582), TAD (0.9799) and CAC (0.969). These trends describe the adsorption processes of $\mathrm{Cd}$ and $\mathrm{Cr}$ uptake on the activated carbon. This shows the overall rate of the adsorption process was controlled by chemisorption and involves valence forces, via exchange of electrons between the adsorbents and adsorbate (Ho and McKay, 1999). Cu uptake on UAD followed the trend of chemisorptions while uptake on TAD and CAC followed the trend of non-conformity with the second-order kinetics model. The second-order kinetics is applicable to the system on $\mathrm{Cd}, \mathrm{Cr}$ and the $\mathrm{Cu}$ - 
UAD; since the plot of t/qt versus $t$ with linear relationship (Itodo et al., 2011). A fairly close agreement between the qt (exp) and qt (Cal) were recorded.

\section{Elovich kinetic model}

The coefficient regression values for this model Cd-UAD (0.7538), TAD (0.8625) and CAC (0.8051); Cr-UAD (0.528), TAD (0.3575) and CAC (0.4649); Cu-UAD (0.748), TAD (0.5979) and CAC (0.5083); Pb-UAD (0.7437), TAD (0.8133) and CAC (0.7615). These values are similar to that of film diffusion model and indicated high degree of non-conformity to the model, and hence the active sites on some adsorbents are not heterogeneous; however, the poor trend of linearity cannot account for the sorption rate of this study (Namasivayam and Kuvitha 2009). The chemisorptions reactions involving adsorbate onto solid surfaces without desorption of products, adsorption rate decreases with time due to an increased surface coverage. Elovich is one of the useful models used to describe such activated chemisorptions ( $G$ unay et al., 2007). The active sites of this kinetic law are heterogeneous in nature and therefore exhibit different activation energy of chemisorptions (Masood et al., 2009).

\section{Adsorption Diffusion Models}

\section{Intraparticle diffusion model}

The coefficient regression values for this model Cd-UAD (0.7321), TAD (0.9734) and CAC (0.6752); Cr-UAD (0.5348), TAD (0.8057), and CAC (0.7513); Cu-UAD (0.4889), TAD (0.7394) and CAC (0.832); Pb-UAD (0.6162), TAD (0.7547) and CAC (0.7104). This is very obvious from the high coefficient of regression generated above that the boundary layer has significant effect about the diffusion mechanism of metal uptake on the derived adsorbents and commercial activated carbon implicating diffusion as a determining parameter in the adsorption process. This model explains the movement of adsorbate across the external surface sites on the adsorbent particle (Choy et al. 2004). The linear plot of qe vs $\mathrm{t}^{0.5}$ with intercept greater than zero but close to the origin indicates that interparticles diffusion alone does determine the overall rate of adsorption process (Srivastava et al., 2006).

\section{Film diffusion model}

The liquid film diffusion model plots of $\ln (1-\mathrm{F})$ vs $\mathrm{t}(\mathrm{min})$ was plot for metals as presented in figures 32-35. The coefficient regression values for this model Cd-UAD (0.1475), TAD (0.8502) and CAC (0.1443); Cr-UAD (0.1376), TAD (0.1576) and CAC (0.1474); Cu-UAD (0.7863), TAD (0.7907) and CAC (0.1446); Pb-UAD (0.139), TAD (0.9799) and CAC (0.1423). It is obvious from the very low regression value above that the boundary layer has less significant effect, indicating film diffusion that does not determine the rate of adsorption and does not show good fit and non-applicability to this model, given by their $\mathrm{R}^{2}$ values (Mohanty, et al., 2005). The intercept values for the adsorbents are lower and close to origin, confirming liquid film diffusion as a non-determinant rate of adsorption process (Suguna et al., 2010; Itodo et al., 2011). 


\section{Adsorption Thermodynamic Study}

From the table 6-9, have been observed that with increase in temperature, adsorption capacity increases. This means that for the initial metal concentration of each solution, there is an indication that the reaction of adsorption process is endothermic in nature, of which chemisorptions dominates physisorption (Bai et al., 2010).

The thermodynamic values change in Gibb's free energy $\left(\Delta \mathrm{G}^{\circ}\right)$, change in enthalpy $\Delta \mathrm{H}^{\mathrm{o}}$ and change in enthropy $\left(\Delta \mathrm{S}^{\circ}\right)$ for the adsorption of metals $(\mathrm{Cd}, \mathrm{Cr}, \mathrm{Cu}$ and $\mathrm{Pb})$ over adsorbents (UAD, TAD and CAC) were determined using equation 10 The positive values explains the increase of metals adsorption efficiency as the temperature increased until equilibrium was attained, this positive trends indicated for an disorder at solid/liquid phase during metals adsorption onto adsorbents and also indicated that adsorption process was spontaneous (Azraa et al., 2012).

\section{Statistical Analysis}

ANOVA is one of the dependent tools used in testing the first principles or hypothesis. The ANOVA is based on the effect of time on percentage removal of metals were tested using the adsorbents, the result from one-way ANOVA as shown (Table 2-6) indicates that; in UAD there is significant difference yield for the elements with F-statistics of 161.148 at) $=0.000$ significance level, TAD yields no significant difference for the elements with F-statistic of 2.734 at $\mathrm{P}=0.078$ significance level, while $\mathrm{CAC}$ shows that there is a significant difference for the elements with F-statistics of 4.890 at $\mathrm{P}=0.013$ significance level. However, the result does not indicate which of the elements defer from one another. Consequently, the need to follow the analysis with post-hoc test arose.

Student-Newman-Keuls Post-hoc. Comparisons of the four elements indicates that the UAD and CAC are significantly different while the elements on TAD indicates no level of significant difference and requires no need for post-hoc test at $\mathrm{P}<.05$.

\section{Conclusion}

Physical observation and physico-chemical parameters are signs that discharging brewery effluents into the environment (water bodies and agricultural soils) could be detrimental to the environment, agricultural produce and human health respectively.

The comparable level of percentage removal using the adsorbent is an indication of economic viability of adsorbent.

The kinetic equilibrium study shows that adsorbtion of metals from brewery effluent is best modeled using UAD, TAD and CAC. The correlation coefficient $\mathrm{R}^{2}$ value favours the pseudosecond-order-model, an indication of chemisorptions mechanism as indicated by the experimental data. Transport or diffusion of metals through the adsorbent studied implicate film diffusion model as responsible for the transport of metal onto the adsorbents.

AAS analysis shows the level of heavy metals in the brewery effluents to be above NESREA and WHO permissible limit and could pose as potential threats to the populace; however, results from this study showed a removal efficiency of up to $85 \%$.. 
In general, adsorbent of granular activated carbon and its adsorption studies were sufficiently carried out. Results obtained compares favorably well with those of other adsorbents reported in literatures as it does compare well with the commercial activated carbon for the brewery effluent remediation.

\section{Recommendations}

Following the highlights of the research, the list below was recommended.

i. The possible danger of pollutants to the environment (water and agricultural soil) should be made known to the general public living in the industrial (brewery) area.

ii. The use of other adsorption models should be engaged in testing data generated from adsorption and kinetic studies brewery effluents .

iii. More adsorption (regeneration cycles) should be considered to verify the potential of the adsorbents .

iv. The use of Batch adsorption and computational studies should be exploited in future work .

v. Kaduna brewery and other breweries should consider the use of advanced remediation techniques based on adsorption as a possible environmental operation .

vi. Areas of study involving designs and pilot test of effluent treatment plant should be considered.

vii. Brewery industries within the country should be checked foe metals and chemical pollutants resulting from the brewery.

viii. Metal toxicological profiling of brewery workers should be considered to evaluate metal concentration in blood stream of the workers.

ix. Greener and more eco-friendly technologies for brewing should be adopted and developed.

\section{References}

1) Abdus-Salam, N \& Buhari, M. (2014). Adsorption of Alizarin and Fluorescein Dyes on Adsorbent prepared from Mango Seed. Pacific Journal of Science and Technology, 15(1): 232-244

2) Adepoju-Bello, A.A. \& Alabi O.M. (2005). Heavy metals: A review. The Nig. J. Pharm. 37: 41-45

3) Afaj, H.A., Mohammad, R.M., \& Mahmoud N.M. (2015). Removal of phenol from Industrial Effluents using Activated Carbon and Iraqi Porcelanite Rocks - A Comparative Study.Journal of Ministry of Science and Technology. 91: 21-32

4) Ahmed, A.S., Tantawy, A.M., Abdallah, M.E \& Qassim, I.M. (2015). Characterization and application of kaolinite clay as solid phase extractor for removal of copper ions from environmental water samples.International Journal of Advanced Research. 3(3): 1-21

5) Amanda, E.M., Milene, S.P., Alexandre, O.J., Marco, A.U.M., Rafael, I.V.S., Margarida, J.S., and Gustavo, R.C. (2013). The reactive surface of castor Leaf (RicinuscommunisL.) powder as a green adsorbent for the removal of heavy metals from natural river water. Journal of Applied Surface Science, (276): 24-30 
6) Andrew, D., Clesceri, E., Rice, L.S. \& Greenberg, A. E. (2005). "Standard Methods for the Examination of Water and Wastewater," 21st edition, APHA-AWWA-WEF, Baltimore, MD: 1368-1372

7) Anirudhan, T. S., Unnithan, M. R., Divya, L., \& Senan, P. (2007). Synthesis and characterization of polyacrylamide-grafted coconut coir pith having carboxylate functional group and adsorption ability for heavy metal ions.Journal of applied polymer science, 104(6): 3670-3681

8) APHA-American Public Health Association (1995). Standard method for the examination of water and wastewater, 19th Edn. Washington DC. 22-31

9) APHA-American Public Health Association, AWWA-American Water Works Association, WPCF -Workshop on Particle Correlations and Femtoscopy, (2012). Standard Methods for the Examination of Water and wastewater; American Public Health Association, Washington-DC.184-190

10) Aroke U. O1., El-Nafaty U. A and Osha O. A (2013). Properties and Characterization of Kaolin Clay from Alkaleri, North-Eastern Nigeria.International Journal of Emerging Technology and Advanced Engineering, 3(11): 387-392

11) AWWA-American Water Works Association (1995). Standard method for the examination of water and wastewater, 19th Edn. Washington DC. 211-215

12) Aziz, H.A., Yusoff, M.S., Adlan, M.N., Adnan, N.H. \& Alias, S. (2008). Heavy metals. Waste Manag. 24: 353-358

13) Azraa, A., Jain K., Tong K. S., Rozaini C. A. and Tan L. S. (2012). Equilibrium, kinetic and thermodynamic studies on the adsorption of Direct Dye onto a novel green adsorbent developed from Uncaria Gambir. Extract. Journal of Physical Science, Vol. 23(1): 1-13

14) Bai, T.M., Komali, K and ventakeswarhi, P. (2010). Equilibrium, kinetics and thermodynamic studies on biosorption of copper and Zinc from mixed solution by Erythrina Variegata orientalis leaf powder. India Journal of chemical Technology. 17: 346-355

15) Boparai, H.K., Joseph, M., \& O’Carroll, D.M. (2011). Kinetics and thermodynamics of cadmium ion removal by adsorption onto nano zerovalent iron particles. Journal of hazardous materials, 186(1): 458-465

16) Bosnic, M., Buljan J. Daniels R.P. \& Rajamani S. (2003). Pollutants in tannery effluent; International Scenario on Environmental Regulations and Compliance, UNIDO technical assistance project SF/EGY/97/167 managed by FerencSchmél, Industrial Development Officer, Vienna. 67-73

17) Brame, J., Li, Q. \& Alvarez, P. J. (2011). Nanotechnology-enabled water treatment and reuse: emerging opportunities and challenges for developing countries. Trends in Food Science \& Technology, 22(11): 618-624

18) Chae, K.J., Choi, M.J., Lee, J.W., Kim, K. Y, \& Kim, I.S. (2009). Effect of different substrates on the performance, bacterial diversity, and bacterial viability in microbial fuel cells.Biores. Technol.100: 3518-3525

19) Chen, Z., Ma, W., \& Han, M. (2008). Biosorption of Nickel and Copper onto Treated Alga (Undriapinnarlifida). Application of Isotherm and Kinetic Models, J. Hazar.Mater. 155: $327-333$

20) Chien S.H. \& Clayton W.R. (1980). Application of Elovich equation to the kinetics of phosphate release and sorption in soils. Soil Science Society of American Journal. 44:265268. 
21) Choy, K. K. H., Ko, D. C. K., Cheung, C. W., Porter, J. F. \& McKay, G. (2004). Film and intraparticle mass transfer during the adsorption of metal ions onto bone char. Journal of Colloid and Interface Science, 271(2): 284-295.

22) Chuah, T.G., Jumasiah, A., Azni, I., Katayon, S. \& Thomas Choong, S.Y. (2005). Rice husk as a potentially low cost biosorbent for heavy metal and dye removal: An overview. Desalination 175: 305-316.

23) Coonery, D.O. (1999). Adsorption design for wastewater treatment. Lewis Publishers, USA: 182.

24) Cornelissen, G., van Noort, P. C., \& Govers, H. A. (1998). Mechanism of slow desorption of organic compounds from sediments: a study using model sorbents. Environmental science \& technology, 32(20): 3124-3131.

25) Dạbrowski, A., Hubicki, Z., Podkościelny, P., \& Robens, E. (2004). Selective removal of the heavy metal ions from waters and industrial wastewaters by ion-exchange method.Chemosphere, 56(2): 91-106.

26) De Feo, G. \& De Gisi, S. (2014). Using MCDA and GIS for hazardous waste landfill siting considering land scarcity for waste disposal. Waste Manag. 34: 2225-2238.

27) Demirbas, E., Kobya, M., Sentark, E., \& Ozkan, T. (2004). Adsorption Kinetics for the Removal of Chromium (VI) from Aqueous Solution on the Activated Carbons Prepared from Agricultural Waste. Water SA, 30: 533-539.

28) Ding, Y., Jing, D., Gong, H., Zhou, L. \& Yang, X. (2012). Biosorption of aquatic cadmium (II) by unmodified rice straw.Biosour. Technol. 144: 20-25.

29) El Rahman, A., \& Gepreel, M. (2013). Nanotechnology Applications in Water Treatment: Future Avenues and Challenges: A review. In 6th Int. Perspect. Water Resour. Environ. Conf., Izmir, Turkey 91-95.

30) El-Dars, E. S. M. F., Ibrahim, M. H., Farag, B. A. H., Abdelwahhab, Z. M and Shalabi H. E. M. (2016). Preparation, Characterization of Bentonite Carbon Composite and Design Application in Adsorption of Bromothymol Blue Dye. Journal of Multidisciplinary Engineering Science and Technology.Vol.3 (1), 3758-3765.

31) EPA, (2000). Wastewater technology fact sheet chemical precipitation, Washington DC 9-21.

32) EPA, (2015). Toxic and priority pollutants. 7-12.

33) Epete, O.A. \& Horsefall, M. (2011). Preparation and characterization of activatd carbon derived from fluted pumpkin stem waste (Telfairia occidentalis Hook F). Research Journal of Chemical Science, 1(3): 2231-2606.

34) Feng, D., Aldrich, C., \& Tan, H. (2000). Treatment of acid mine water by use of heavy metal precipitation and ion exchange. Minerals Engineering, 13(6): 623-642.

35) Fleischer, M., Sarofim, A. F., Fassett, D. W., Hammond, P., Shacklette, H. T., Nisbet, I. C., \& Epstein, S. (1974). Environmental impact of cadmium: a review by the Panel on Hazardous Trace Substances. Environmental Health Perspectives, 7: 253-259.

36) Florea, A. M., \& Büsselberg, D. (2006). Occurrence, use and potential toxic effects of metals and metal compounds.Biometals, 19(4): 419-427.

37) Foo, K. \& Hameed, B.H. (2010). Insights into the modeling of adsorption isotherm systems.Chemical Engineering Journal, 156(1): 2-10.

38) G"unay A, Arslankaya E. and Tosun I. (2007). Lead removal from aqueous solution by natural and pretreated clinoptilolite: Adsorption equilibrium and kinetics. Journal of Hazardous Material, (146): 362-371. 
39) Gandhi, N., Sirisha, D. \& Chandra S.K.B. (2016). "Adsorption of Fluoride (F-) from Aqueous Solution by Using Pineapple (Ananas comosus) Peel and Orange (Citrus sinensis) Peel Powders."International Journal of Environmental Bioremediation \& Biodegradation, 4 (2): 55-67.

40) Gautam, R.K., Mudhoo, A., Lofrano, G. \& Chattopadhyaya, M.C. (2014). Biomassderived biosorbents for metal ions sequestration.Adsorbent modification and activation methods and adsorbent regeneration, J Eniron. Chem. Eng. 2: 239-259.

41) Ge, F., Li, M. M., Ye, H., \& Zhao, B. X. (2012). Effective removal of heavy metal ions $\mathrm{Cd}^{2+}, \mathrm{Zn}^{2+}, \mathrm{Pb}^{2+}, \mathrm{Cu}^{2+}$ from aqueous solution by polymer-modified magnetic nanoparticles. Journal of hazardous materials, 211: 366-372.

42) Godt, J., Scheidig, F., Grosse-Siestrup, C., Esche, V., Brandenburg, P., Reich, A., \& Groneberg, D. A. (2006). The toxicity of cadmium and resulting hazards for human health.Journal of occupational medicine and toxicology, 1(1): 22-27.

43) Gomez, V., \& Callao, M. P. (2006). Chromium determination and speciation since 2000.TrAC Trends in Analytical Chemistry, 25(10): 1006-1015.

44) Gupta, K.V \& Nayak, A. (2011). Cadmium removal and recovery from aqueous solutions by novel adsorbents prepared from orange peel and $\mathrm{Fe}_{2} \mathrm{O}_{3}$ nanoparticles. Chemical Engineering Journal, 180: 81-90.

45) Gupta, S.S., \& Bhattacharyya, K.G. (2011). Kinetics of adsorption of metal ions on inorganic materials: a review. Advances in Colloid and Interface Science, 162(1): 39-58.

46) Gupta, S.S., \& Bhattacharyya, K.G. (2006). Adsorption of Ni (II) on clays.Journal of colloid and interface science, 295(1): 21-32.

47) Hashem, E.Y., Seleim, M.M., \& El-Zohry, A.M. (2011). Environmental method for spectrophotometric determination of copper (II). Green Chemistry Letters and Reviews, 4(3): 241-248.

48) Hashim, M.A., Mukhopadhyay, S., Sahu, J.N., \& Sengupta, B. (2011). Remediation technologies for heavy metal contaminated groundwater. Journal of environmental management, 92(10): 2355-2388.

49) Heuze, V., Sauvant, D., Tran, G., Lebas, F. \& Lessire, M. (2013). Carob (Ceratonia siliqua) Feedipedia.org.A programme by INRA, CIRAD, AFZ and FAO. 23-31.

50) Hiroyuki, H., Hideki N., \& Kataoka T. (1994). Adsorption of BSA on strongly basic chitosan-Equilibra, Journal of Biotechnology and Bioengineering, 43, 1087-1093.

51) HoY.S.\& McKay G. (1998). The kinetics of sorption of basic dyes from aqueous solution by Sphagnum moss peat. Canadian Journal of Chemical Engineering. 76:822-827.

52) Igwe, J.C. \& Aiba, A.A. (2006), "Sorption kinetics and intra particulate diffusivity of as (III) bioremediation from aqueous solution using modified and unmodified coconut fiber," Eclectica quimica, 31: 3-11.

53) Ince, B.K., Ince, O., Sallis, P.J. \&Anderson, G.K. (2000). Inert COD production in a membrane anaerobic reactor treating brewery wastewater.Water Res. 34(16): 3943-3948.

54) Iwahori, K., Watanabe, J.I., Tani, Y., Seyama, H., \& Miyata, N. (2014). Removal of heavy metal cations by biogenic magnetite nanoparticles produced in Fe (III)-reducing microbial enrichment cultures. Journal of bioscience and bioengineering, 117(3): 333335.

55) Kadirvelu, K., Thamaraiselvi, K., \& Namasivayam, C. (2001). Removal of heavy metals from industrial wastewaters by adsorption onto activated carbon prepared from an agricultural solid waste. Bioresource Technology, 76(1): 63-65. 
56) Karichappan, T., Venkatachalam, S., \& Jeganathan, P.M. (2014). Optimization of electrocoagulation process to treat grey wastewater in batch mode using response surface methodology. Journal of Environmental Health Science and Engineering, 12(1), 29-40.

57) Karthikeyan, M. \& Elongo, K.P. (2008). Removal of Fluoride from Aqueous Solution using Graphite. A Kinetic and thermodynamic Study, Indian J. Chem. Technol. 15: 525532.

58) Li, X., Tabil, L.G., \& Panigrahi, S. (2007). Chemical treatments of natural fiber for use in natural fiber-reinforced composites: a review. Journal of Polymers and the Environment, 15(1): 25-33.

59) Lianxin, Luo., Ye, Jin., Mingfu, Li., Lingyu, Hu., Guangxing, Li., \& Yi, Liu. (2017). Methylene blue adsorption.BioResources 12(2): 2452-2465.

60) Limousin, G., Gaudet, J.P., Charlet, L., Szenknect, S., Barthes, V., \& Krimissa, M. (2007). Sorption isotherms: a review on physical bases, modeling and measurement. Applied Geochemistry, 22(2): 249-275.

61) Maheshwari, U., Mathesan, B. \& Gupta, S. (2015). Efficient adsorbent for simultaneous removal of $\mathrm{Cu}(\mathrm{II}), \mathrm{Zn}(\mathrm{II})$ and $\mathrm{Cr}(\mathrm{VI})$ : Kinetic, thermodynamics and mass transfer mechanism, process. Saf. Environ. 98: 198-210.

62) Makeswari, M. Santhi, T \& Ezhilarasi, M.R. (2016). Adsorption of methylene blue dye by citric acid modified leaves of Ricinus communis from aqueous solutions. Journal of Chemical and Pharmaceutical Research. 8(7):452-462.

63) Marín, A.P., Aguilar, M.I., Meseguer, V.F., Ortuno, J.F., Sáez, J., \& Lloréns, M. (2009). Biosorption of chromium (III) by orange (Citrus cinensis) waste: batch and continuous studies.Chemical Engineering Journal, 155(1): 199-206.

64) Masri, M., Reuter, F.W., \& Friedman, M. (1974). Binding of metal cations by natural substances.Journal of Applied Polymer Science, 18(3): 675-681.

65) Nagajyoti, P.C., Lee, K.D., \& Sreekanth, T.V.M. (2010). Heavy metals, occurrence and toxicity for plants: A review. Environmental Chemistry Letters, 8(3): 199-216.

66) Nakayama, T., Arai, M., \& Nishiyama, U.J. (1984). /Article/Chemiport/. Catal.87 : 108115.

67) Namasivayam C. and Kavitha D. (2009). Removal of Congo red from water by adsorption on activated carbon prepared from coir pith, an agricultural waste. Dyes and pigments, 54:47-58.

68) Nuhoglu, Y.\&Maloc, E. (2009). Thermodynamic and kinetic studies for environmental friendly $\mathrm{Ni}$ (ii) biosorption using waste pumice of olive oil. Journal of Bioresource Technology. 100:2375-2380.

69) O’Connell, D.W., Birkinshaw, C., \& O’Dwyer, T.F. (2008). Heavy metal adsorbents prepared from the modification of cellulose: A review. Bioresource technology, 99(15): 6709-6724.

70) Okewale, A.O., Igbokwe, P.K. \& Babayemi, K.A. (2015). Kinetics Modeling of the Column Adsorption for The Dehydration of Ethanol - Water Mixtures using Biomass Adsorbents.J. Chem. Eng. Process Technol. 6: 217-303.

71) Owlad, M., Aroua, M.K., Daud, W.A.W. \& Baroutian, S. (2009). Removal of hexavalent chromium-contaminated water and wastewater: A review. Water, Air, and Soil Pollution, 200(1-4): 59-77. 


\section{1 | International Journal of Scientific and Management Research 4(6) 14-52}

72) Palanisamy, P.N, \& Sivakumar, P. (2009). Adsorption Studies of Basic red 29 by a NonConventional Activated Carbon Prepared from Euphorbia Antiguorum L. Inter. J. Chemtech. Res. 1: 502-506.

73) Parawira, W., Kudita, I., Nyandoroh, M.G. \& Zvauya, R. (2005). A study of industrial anaerobic treatment of opaque beer brewery wastewater in a tropical climate using a fullscale UASB reactor seeded with activated sludge. Process Biochem. 40(2): 593-599.

74) Pillai, M.G., Simha, P. \& Gugalia, A. (2014). Recovering urea from human urine by biosorption onto microwave activated carbonized coconut shells: equilibrium, kinetics, optimization and field studies. J. Environ. Chem. Eng. 2 (1): 46-55.

75) Qiu, H., Lv, L., Pan, B.C., Zhang, Q.J., Zhang, W.M., \& Zhang, Q.X. (2009). Critical review in adsorption kinetic models.Journal of Zhejiang University-Science A, 10(5): 716-724.

76) Richard, F.C., \& Bourg, A.C. (1991). Aqueous geochemistry of chromium: a review. Water research, 25(7), 807-816.

77) Satapathy D. \& Natarajan G.S. (2006): Potassium bromated modification of the granular activated carbon and its effect on nickel adsorption. Adsorption, 12: 147-154.

78) Speece, R.E. (1996). Anaerobic biotechnology for industrial wastewater. Archae, Nashville, TN 13-21.

79) Suguna, M., Siva, K.N., Venkata, S.M. \& Krishnaiah A. (2010). Removal of divalent manganese from aqueous solution using Tamarindusindica Fruit Nut Shell.Journal of Chemical and Pharmaceutical. Research, 2(1): 7-20.

80) Taha, M.E., Zeinhom H.M., Walied S. \&Ahmed M.I. (2014). Kinetic and Equilibrium Isotherms Studies of Adsorption of $\mathrm{Pb}$ (II) from Water onto Natural Adsorbent. Journal of Environmental Protection. (5): 1667-1681.

81) Theron, J., Walker, J.A. \&Cloete, T.E. (2008). Nanotechnology and water treatment: applicationsand emerging opportunities. Crit. Rev. Microbiol. 34: 43-69.

82) Uslu, H. \& Inci, I. (2009). Adsorption Equilibria of L - (+) - Tartaric Acid onto Alumina.J. Chem. Eng. Data, 54: 1997-2001.

83) Veena, D.B., Jahagirdar A.A. \& Zulfiqar A.M.N. (2012). Adsorption of Chromium on Activated Carbon Prepared from Coconut Shell. International Journal of Engineering Research and Applications; 2(5): 364-370.

84) Volesky, B., \& Holan, Z. R. (1995).Biosorption of heavy metals.Biotechnology progress, 11(3): 235-250.

85) Wang, S.G., Liu, X.W., Gong, W.X, Gao, B.Y., Zhang, D.H. \& Yu, H.Q. (2007). Aerobic granulation with brewery wastewater in a sequencing batch reactor.Bioresour. Technol. 98(11): 2142-21.

86) Wang, S.G., Liu, X.W., Gong, W.X, Gao, B.Y., Zhang, D.H. \& Yu, H.Q. (2007). Aerobic granulation with brewery wastewater in a sequencing batch reactor.Bioresour. Technol. 98(11): 2142-2147

87) WHO \& UNICEF (2013). Progress on sanitation and drinking water.21-25.

88) Yu, B., Zhang, Y., Shukla, A., Shukla, S.S. \& Dorris, K.L. (2000). The removal of heavy metal from aqueous solutions by sawdust adsorption removal of copper.J. Hazard. Mater. 80: 33-42.

89) Zawani, Z., Luqman, C.A., Choong, T.S.Y. (2009). Equilibrium kinetics and thermodynamic studies: Adsorption of Remazol black 5 on the palm kernel shell of activated carbon (PKS-AC). European Journal of Scientific Research, 37:67-71. 
52 | International Journal of Scientific and Management Research 4(6) 14-52

90) Zhang, J., \& Stan forth, R. (2005). Slow Adsorption Reaction between Arsenic Species and Geothite. Diffusion or Heterogeneous Surface Reaction Control, Langmuir 21, 28952901.

91) Zhao, G., Wu, X., Tan, X. \& Wang, X. (2011). Sorption of heavy metal ions from solutions: A review, Open Collid Sci. J. 4: 19-31. 